\title{
Shifts in Non-Income Welfare in South Africa:
}

\section{3-2004}

\author{
Haroon Bhorat \\ Pranushka Naidoo \\ Carlene van der Westhuizen \\ Development Policy Research Unit \\ cvdwesthuizen@commerce.uct.ac.za
}




\section{Acknowledgement}

Funding was contributed by the Conflict and Governance Facility, a project of National Treasury, which is funded by the European Union under the European Programme for Reconstruction and Development.

Development Policy Research Unit Tel: +27 216505705

Fax: +27 216505711
Information about our Working Papers and other published titles are available on our website at: http://www.commerce.uct.ac.za/dprul 


\section{Abstract}

The aim of this study is to provide an analysis of the shifts in non-income welfare that have occurred over the period 1993 to 2004. This analysis serves as a complement to existing research which has focused on shifts in income poverty and inequality in the post-apartheid period. In addition, the study is one of only a few that provides a complete overview of the first decade of democracy by means of the comprehensive time period it covers. We use a technique called factor analysis to construct an asset index as an alternative, non-income based, measure of welfare. Variables reflecting household access to a range of services and assets are used in the construction of our asset index.

An initial descriptive overview of the shifts in access to services and assets provides strong evidence that government asset and service delivery between 1993 and 2004 was pro-poor in nature. When standard measures of poverty are applied to our asset index values, statistically significant decreases in the headcount asset poverty rates between 1993 and 2004 across a range of covariates are found. A series of inequality measures are also applied to our asset index. The estimates show that across all covariates, asset inequality decreased between 1993 and 2004. Inequality decompositions indicate that within-group inequality has increased in importance in determining aggregate inequality. 


\section{Table of Contents}

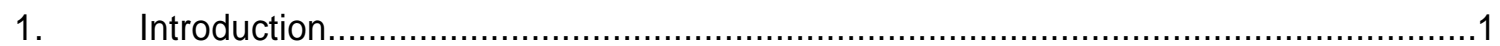

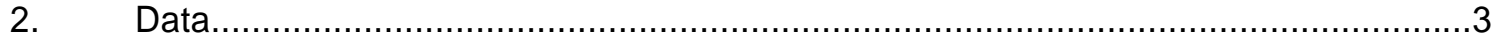

3. An Overview of Shifts in Access to Services and Assets: 1993 to $2004 \ldots \ldots \ldots \ldots \ldots \ldots \ldots$

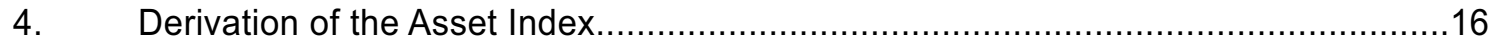

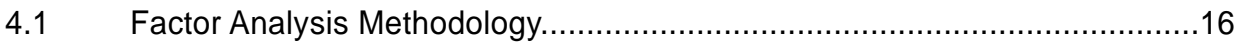

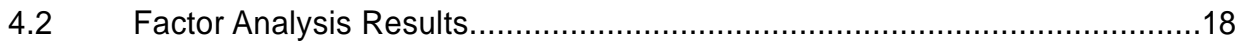

5. Measures of Non-Income Vulnerability.....................................................22

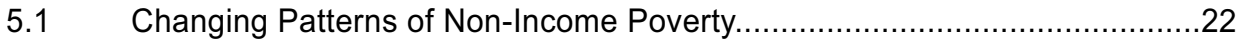

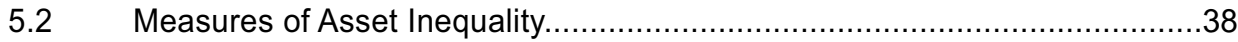

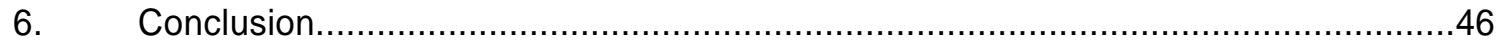

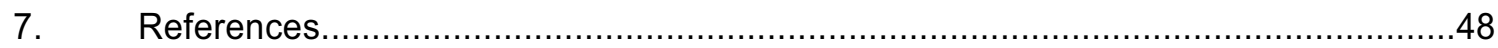

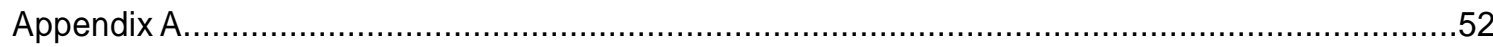

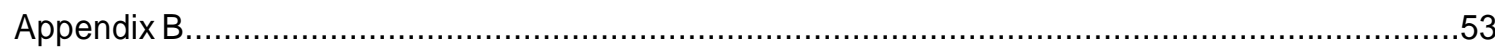

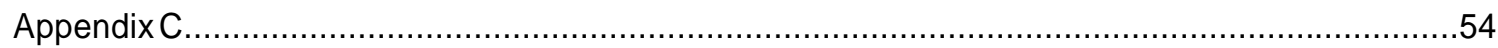

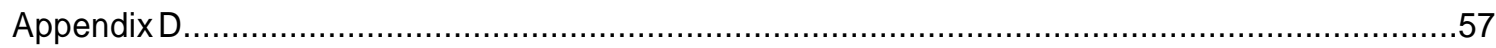

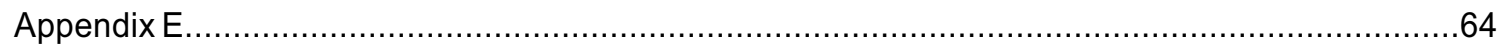

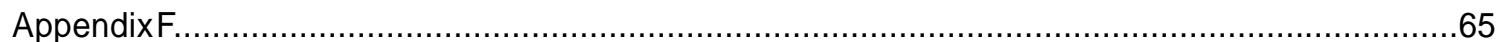

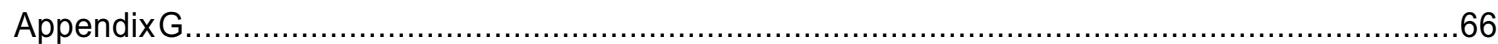

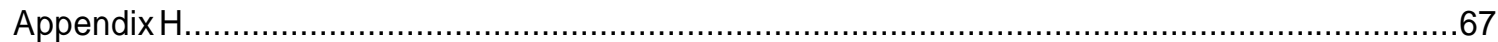

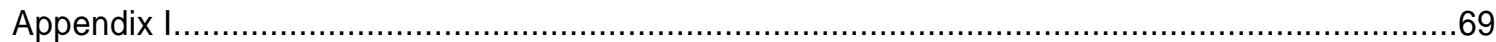

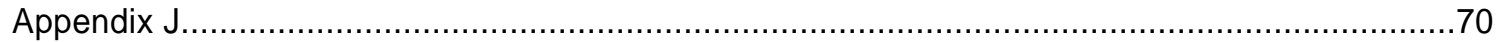

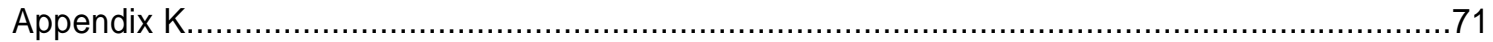

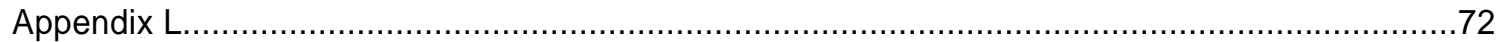




\section{Introduction}

The advent of 10 years of democratic rule in South Africa, combined with availability of more recent survey data sets, sparked a research agenda within the local economics fraternity focusing, in part, on the welfare shifts that had occurred in the society since 1994. The work within this broad area, has thus far, focused almost exclusively on understanding the changes in income poverty and inequality in the post-1994 period. Hence, this recent literature has derived estimates of household poverty and inequality, that indicate either no change or a slight, statistically significant increase in the headcount measure of poverty (Hoogeveen and Özler, 2006; van der Berg, 2006; Leibbrandt, Levinsohn \& McCrary, 2005; Leibbrandt, Poswell, Naidoo, Welch \& Woolard, 2005). The evidence on income inequality indicates marginal increases in the Gini coefficient in most of the studies (Hoogeveen and Özler 2006; Leibbrandt, Levinsohn \& McCrary, 2005; Leibbrandt, Poswell, Naidoo, Welch \& Woolard, 2005).

The importance of these results cannot be doubted, and indeed, they serve as a vital ingredient in our initial assessment of the social and economic progress made in the postapartheid period. However, this research is marked by two key drawbacks. Firstly, all the existing work focuses as is common practice, on an income metric (differentially measured) of poverty and inequality. Hence, through the use of expenditure- or consumptionbased measures of income, changes in absolute and relative poverty, as well as income inequality, are provided. Secondly, this body of research, with the exception of one of these studies, is not in fact a representation of the first decade of democracy. In covering the period 1995-2000 or 1996-2001, depending on the data sets used, these results obviously cover an incomplete time period. The non-availability of more recent data sets forced this time-period choice.

Given the above, we attempt here to provide an analysis of the shifts in non-income welfare that have occurred over the period 1993-2004. In so doing, we are able to examine the changes that have occurred in households' levels of entitlement deprivation, over a more representative time period. Key to our approach here is the use of factor analysis, in deriving these different measures. We view this paper therefore, as a complement to the literature on post-apartheid welfare shifts. Furthermore, within the context of how positive economic growth, recorded steadily over the post-1994 period, has impacted on relative and absolute income levels, the provision of assets and services by the state serves as an important counterpoint to the debate on the socio-economic progress made in the post-1994 era.

Section 2 of this paper discusses the data used in the analysis. Section 3 provides a brief descriptive overview of the changes in access to assets and services between 1993 and 2004. Section 4 describes the methodology used in our analysis (Section 4.1) and 
presents the results of the application (Section 4.2). In Section 5 the derived poverty and inequality measures are discussed. Section 6 concludes. 


\section{Data}

Three sources of data were utilised in our analysis. The choice of datasets was guided to a large extent by the period under analysis as well as the type of information contained in all the available datasets. We opted not to use the Census 1996 and Census 2001 as sources of data. The period under consideration would have been relatively short (five years) and would have covered less than half of the "post-apartheid" period. In addition, the Census 1996 only recorded the household ownership of one asset, namely the presence of a telephone and/or cellular phone.

The first source of data is the 1993 South African Integrated Household Survey from the Project for Statistics on Living Standards and Development (PSLSD). This survey, conducted by the South African Labour Development Research Unit (SALDRU) at the University of Cape Town's School of Economics was South Africa's first representative multi-purpose household survey. The survey collected a wide range of information on different aspects of living standards from a sample of approximately 9000 households. The issues covered, to name a few, included demography, household services, household expenditure, land access and use, employment and income. The SALDRU data has been re- weighted with weights from the 1991 Census and corrected for enumeration difficulties. ${ }^{1}$

The second data source is the 1999 October Household Survey (OHS). The October Household Survey was conducted by Statistics South Africa on an annual basis between 1994 and 1999. The aim of the survey was the collection of data on a wide range of development and poverty indicators. The 1999 OHS collected information on people living in 30000 households across South Africa (StatsSA, 2000: i). The data used in our analysis has been weighted using the 1996 Census weights.

The third data source is the 2004 General Household Survey (GHS). The GHS is an annual survey conducted by Statistics South Africa since 2002. The survey was introduced to capture information on the living conditions of South African households that will allow the evaluation of government programmes and projects (StatsSA, 2003: i). The broad areas covered by the survey are education, health, the labour market, housing and household access to services and facilities as well as household assets (StatsSA, 2005: i). During the 2004 survey, 26345 households were interviewed and the dataset has been benchmarked to mid-year population estimates released in 2005 (StatsSA, 2005: ii).

1 For more information on the 1993 SALDRU survey see http://www.cssr.uct.ac.za/saldru_pslsd.html 
All three datasets were cleaned and aligned to enable accurate comparisons between the three years. Variables were renamed to ensure uniformity. In addition, all variables not used in the analysis were removed from the datasets and the three "clean" datasets used in our analysis only contain household level information.

Before moving on to the discussion and application of the factor analysis methodology, Section 3 provides a brief descriptive overview of the shifts in households' access to assets and services between 1993 and 2004. This section contains a relatively straightforward analysis of the changes in the proportion of households who had access to a range of services and assets. It allows us to make preliminary comments on the scope of government service delivery over the period as well as serving as a benchmark for the results of our factor analysis. 


\section{An Overview of Shifts in Access to Services and Assets: 1993 to 2004}

One of the key policy objectives enunciated repeatedly by government in the post-1994 period has been the provision of free basic services. This includes the electrification of all households and the provision of free basic electricity to poor households $(50 \mathrm{kWh}$ per household per month ${ }^{2}$ ) to all households as well as the provision of free basic water (up to 6 kiloliters of water to all households) and sanitation (National Treasury, 2003: 207, 230). In addition, the provision of low-cost housing is one of Government's core pro-poor programmes adopted in 1994 (National Treasury, 2003: 159). Our three datasets contain information on the number of households who had access to a range of basic services in the three years under consideration. For our purposes, we analysed the changes in access to formal dwelling, piped water, electricity and sanitation.

Growth Incidence Curves (GICs) were constructed to illustrate the increase in access rates to these services between 1993 and 2004. In addition, the growth incidence curves allow us to evaluate how households have benefited from increased government delivery of services relative across the expenditure distribution. Methodologically we draw on the work of Ravallion (2004) and Chen and Ravallion (2003), who developed the concept of GICs. In their application of the methodology, the GIC gives the rate of growth (in per capita income or expenditure) over a certain time period at each percentile of the distribution (ranked by per capita income or expenditure) (Ravallion, 2004: 4). The GIC approach allows us therefore to determine whether growth in income/expenditure in a period has been pro-poor in nature - by plotting the growth in access to the asset or service across each centile of the distribution.

Given data constraints, we calculate the rate of growth in household access rates to certain government services between 1993 and 2004, by per capita household expenditure decile. ${ }^{3}$ Figures 1 to 5 present the GIC curves for the poorest four per capita household expenditure deciles. In addition, the growth in the total household access rate to the particular asset is given as well as the mean growth in access rates for the bottom (poorest) four per capita household expenditure deciles.

2 See Department of Minerals and Energy, 2003.

3 The 1999 and 2004 datasets do not report actual income but rather income in bands, hence we utilise deciles rather than centiles for the expenditure distribution. 
Figure 1: Growth Incidence Curve: Access to Formal Dwelling, 1993 - 2004

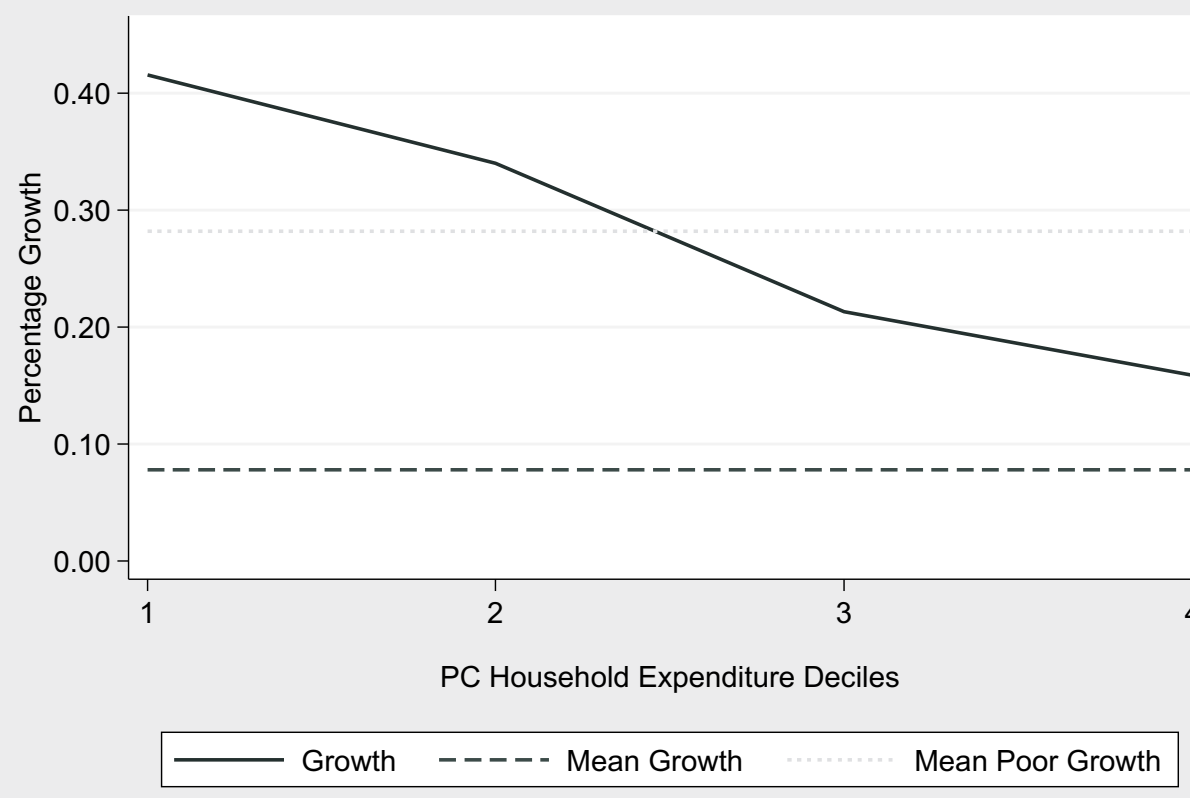

Source: PSLSD 1993 (SALDRU), GHS 2004 (Statistics SA); Own Calculations

Figure 1 shows that between 1993 and 2004, the share of all households in South Africa who had access to a formal dwelling increased by 8 per cent. The GIC shows that the poor - represented here by those in the bottom four deciles - benefited both in relative and absolute terms ${ }^{4}$ from the increased access to formal dwellings. In fact, the growth rate of 28 per cent in the poorest decile's access to formal dwellings was more than five times the national mean of 8 per cent. In addition, households in the second decile experienced a 34 per cent growth in their access rate, followed by 21 per cent for the third decile and 16 per cent for the fourth poorest decile. These figures are strongly indicative of the propoor nature of housing delivery in this first decade of South Africa's democracy.

Figure 2 presents the GIC for access to piped water between 1993 and 2004, and illustrates that the total household access rate to piped water increased by 14 per cent. Over the same period, the poor again benefited both in absolute and relative terms from the increased delivery of piped water, with the mean growth rate in the access rates of the bottom four expenditure deciles six times the growth rate in total household access

$4 \quad$ Pro-poor growth can be considered "absolute" if the change in access to a certain service of the poor (as defined by a chosen poverty line - in this case the poorest 40 per cent of the population) over a given time period is larger than zero, i.e. the access levels of the poor have increased in absolute terms. Pro-poor growth can be considered "relative" if the growth in the access rates of the poor is larger than the growth in the access rates of the non-poor. 
rate. Households in the bottom per capita household expenditure decile experienced an increase of 187 per cent in their access rate, while the households in the second decile saw their average access rate increase by 76 per cent. Households in the third and fourth deciles experienced an increase in their access rates of 41 per cent and 31 per cent respectively.

Figure 2: Growth Incidence Curve: Access to Piped Water, 1993 - 2004

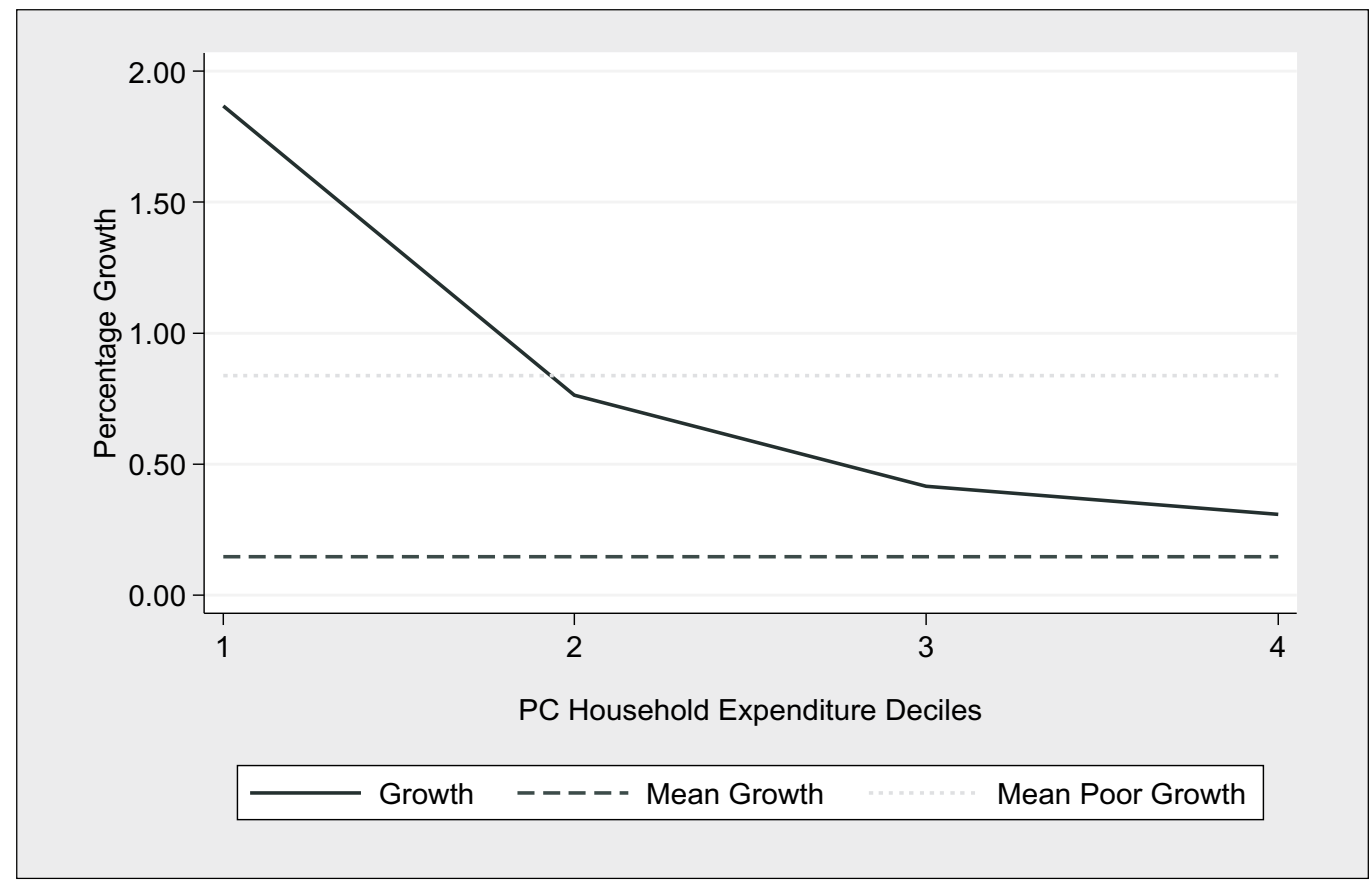

Source: PSLSD 1993 (SALDRU), GHS 2004 (Statistics SA); Own Calculations

Again, the fact that the households in the poorest decile saw their piped water access increase by six times that of the households in the fourth decile is strongly indicative of the "relative nature" of this pro-poor growth in service access. Note that, the fourth decile's increase in access was still more than double the increase at the national level. It bears mention that in comparison with the delivery of formal housing, the pace of delivery of piped water has been extremely rapid over the period. This is indicative of the state's ability to address long-standing backlogs in a short spate of time. It also, however, strongly reflects the effectiveness of a specific government department or the relatively 
ineffectiveness of other departments, to translate expenditure allocations into tangible outcomes.

While both the PSLSD 1993 and the GHS 2004 included a question on household access to a main electricity supply, a similar question was not included in the 1999 OHS. In our factor analysis which follows below, two alternative variables related to energy sources and electricity were included, namely source of energy for lighting (electricity, paraffin or candles) and source of energy for cooking (electricity, paraffin, wood). Figure 3 presents growth in household use of electricity for lighting between 1993 and 2004 . The growth in the use of electricity for cooking between 1993 and 2004 is presented in Appendix A.

Figure 3: Growth Incidence Curve: Use of Electricity for Lighting, 1993 - 2004

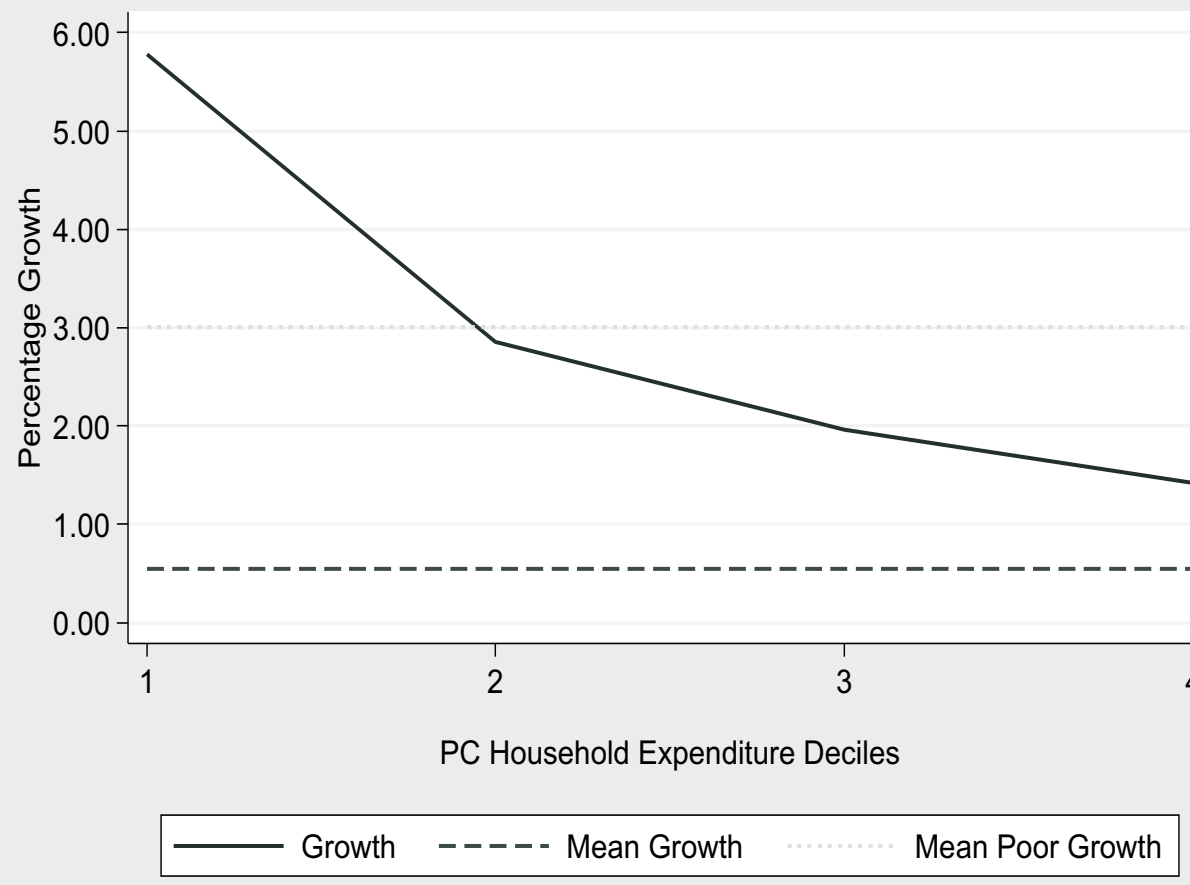

Source: PSLSD 1993 (SALDRU), GHS 2004 (Statistics SA); Own Calculations 
Between 1993 and 2004, the share of all households that use electricity as source for lighting increased by 55 per cent. The growth in the use of electricity for lighting was strongly pro-poor both in both absolute and relative terms. The share of all poor households (defined as the bottom four expenditure deciles) using electricity for lighting increased by a massive 300 per cent over the period, which is more than five times the national average. The share of households in the poorest expenditure decile utilising electricity as source for lighting increased by almost 600 per cent - more than ten times the average increase for all households and four times that of households in the fourth decile. Households in the second decile experienced a 286 per cent increase, with a 197 per cent increase in the third decile and 142 per cent increase in the fourth decile.

While the data is provided in Appendix $A$, the evidence indicates that the share of households consuming electricity for cooking increased by 31 per cent between 1993 and 2004. This is lower than the mean growth rate of 55 per cent in the use of electricity for lighting over the same period. This outcome may be a function of the fact that some households do not own the appliances required for electricity-based cooking. In addition, some households may prefer to use other sources of energy (wood or paraffin for example) when cooking.

Again, the poorest four deciles increased their use of electricity for cooking at a much higher rate than the increase for all households. In fact, the increase in use of electricity for cooking was more pro-poor than the increase in the use of electricity for lighting. This is illustrated by the fact that the increase in the bottom decile of 593 per cent was almost 20 times the increase for all households and five times that of households in the fourth decile. On average the proportion of poor households utilising electricity for cooking increased by 286 per cent. Households in the bottom expenditure decile experienced an increase of almost 600 per cent, followed by 286 per cent in the second decile, 150 per cent in the third decile and 114 per cent in the fourth decile.

In contrast to the large total increases in the household use of electricity, Figure 4 shows that the share of total households with access to a flush or chemical toilet only increased by nine percent between 1993 and 2004 . 
Figure 4: Growth Incidence Curve: Access to Flush/Chemical Toilet, 1993 - 2004

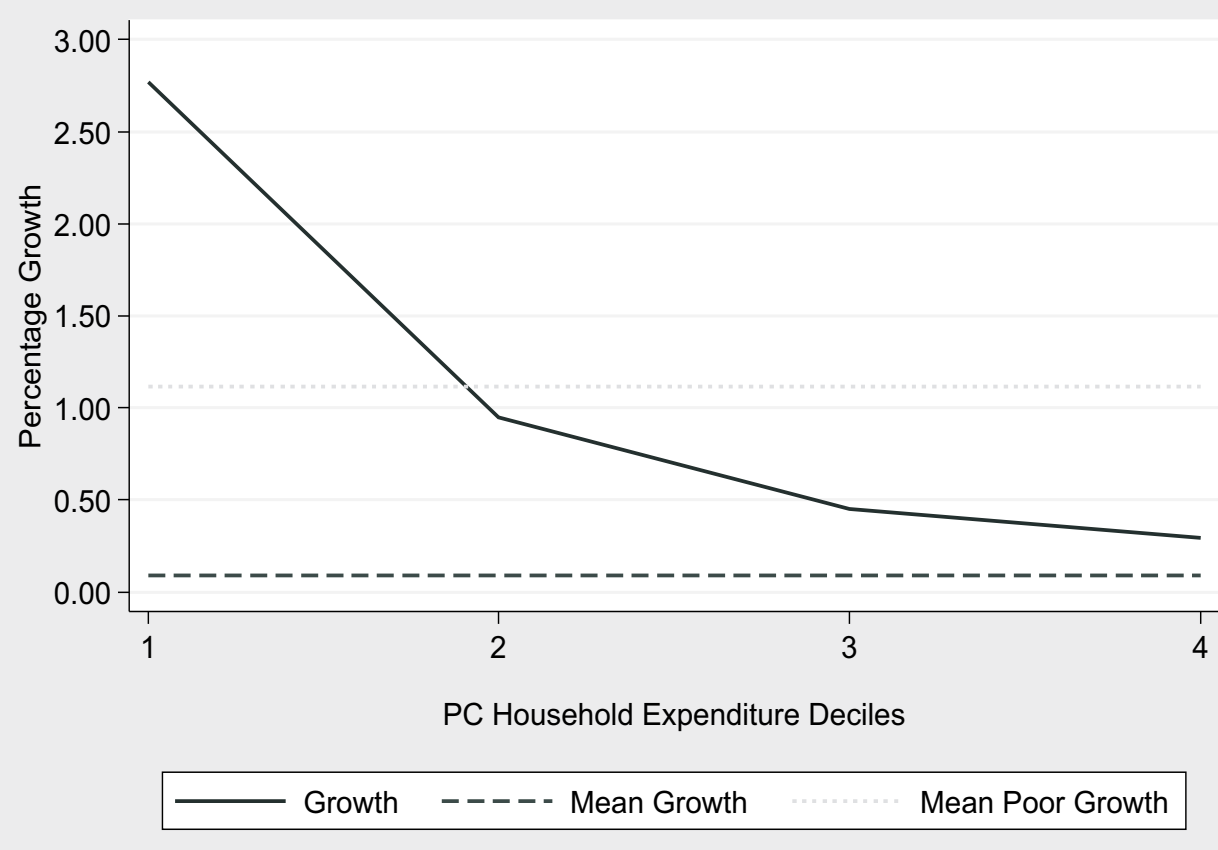

Source: PSLSD 1993 (SALDRU), GHS 2004 (Statistics SA); Own Calculations

This increase, however, was heavily in favour of the poorest households with the average increase in the poorest four expenditure deciles 112 per cent. Households in the bottom decile experienced an increase of almost 300 per cent in their access rates to flush/ chemical toilets, which was more than 30 times the average increase for all households and almost ten times the increase in the fourth decile. Again this is very strong evidence of the absolute and relative pro-poor nature of delivery of flush/chemical toilets. 


\section{Non-linearity in the Growth of Service Delivery}

Figures 1-4 presented the GICs for the period 1993 to 2004 . When we include the access to service rates for 1999 in our analysis, we can present the increase in access to services for the 1993 to 1999 period and again for the 1999 to 2004 period. The 1999 figures, therefore, serve as rough midpoint estimates for the total period and allow us to contrast the pace of government service delivery between the first and the second half of the first decade of democracy.

The evidence suggests that there was non-linearity in the growth in service delivery over the total period. Figure 5 presents household access rates for the household services in 1993, 1999 and 2004. When the changes in access rates between 1993 and 1999 are compared with those that occurred in the second period, 1999 to 2004, it appears that access to these household services grew at a much faster rate in the first period, implying a slowing down of the rate of government service delivery between 1999 and 2004 .

Figure 5: Household Access to Services, 1993 - 1999 - 2004

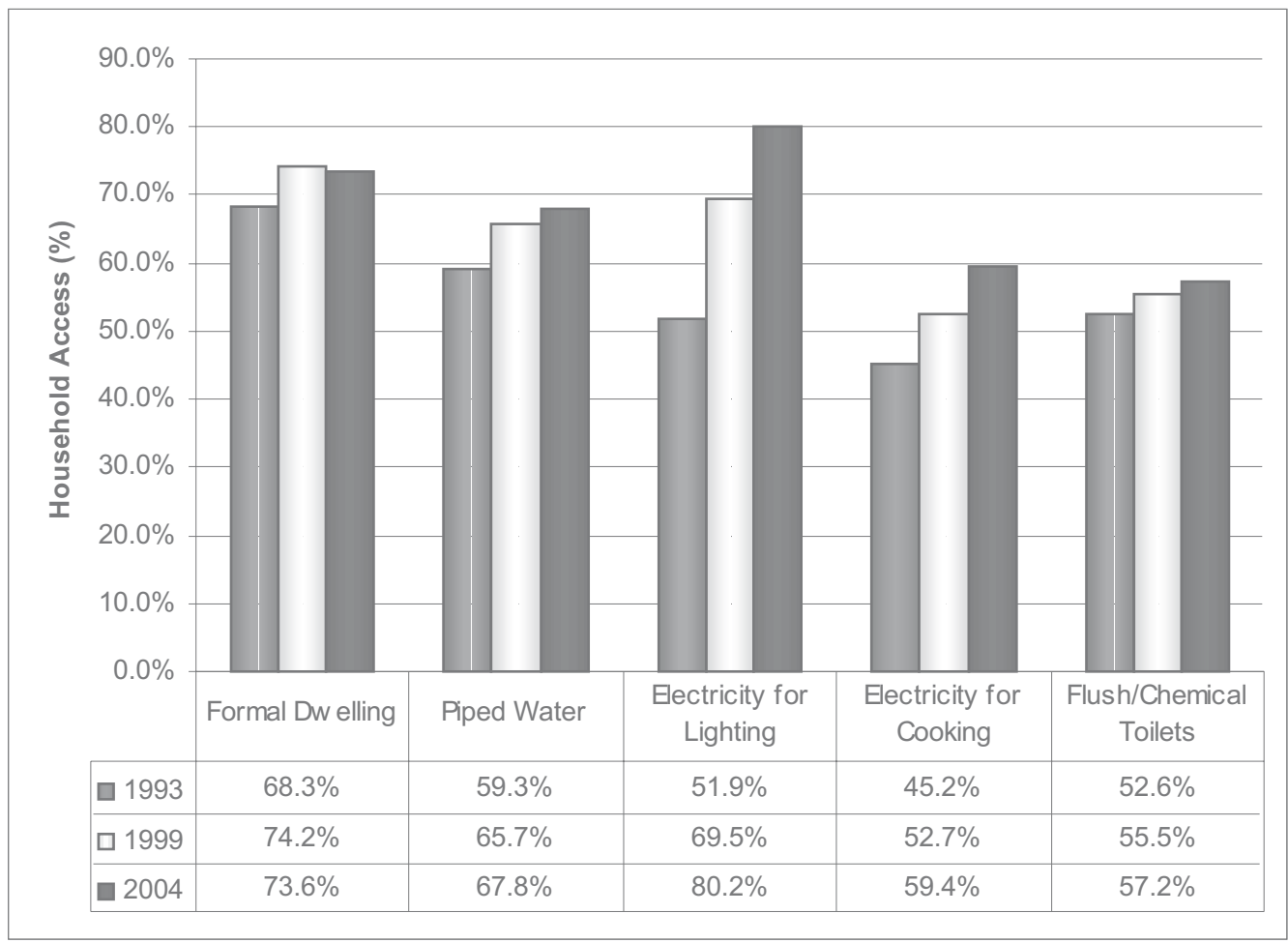

Source: PSLSD 1993 (SALDRU), OHS 1999 (Statistics SA), GHS 2004 (Statistics SA); Own Calculations 
For example, three quarters of the total increase of 8,5 percentage points in household access to piped water between 1993 and 2004 took place between 1993 and 1999. Sixty four per cent of the total growth in access to flush/chemical toilets took place between 1993 and 1999, when the access rate increased by 2,9 percentage points. The access rate only increased by another 1,7 percentage points between 1999 and 2004 . More than 60 per cent of the increase of 17,6 percentage points in the aggregate household use of electricity for lighting took place in the first half of the overall period, while just over half of the increase in the use of electricity for cooking took place between 1993 and 1999.

In the case of household access to formal dwelling, after increasing by 5,9 percentage points to 74,2 per cent, the proportion of the total number of households with access to a formal dwelling decreased very slightly to 73,6 per cent in 2004. It should, however, be kept in mind that the absolute number of households with access to formal dwellings did increase over the period. The decline in the access rate between 1999 and 2004 may be explained by the ever increasing housing backlog in the country. The continuing increases in formal housing backlogs has partly been the result of higher than anticipated increases in the number of households in the country, driven by the decline in the average household size (see National Treasury, 2005: 683).

The changes in household ownership of selected assets (telecommunications, vehicles, radios and televisions) between 1993, 1999 and 2004 are presented in Appendix B. The increase in ownership of telecommunications is particularly striking and in contrast to the growth in delivery of other services and assets, most of the growth took place between 1999 and 2004. Ownership of telecommunications increased by more than 20 percentage points over that period, in contrast to an increase of less than six percentage points between 1993 and 1999. This trend is mainly a reflection of the massive increase in cell phone ownership in the country since the late 1990's. Vehicle ownership declined by almost three percentage points between 1993 and 2004, while radio ownership increased very slightly. Television ownership increased by about 12 percentage points between 1993 and 2004, with approximately three quarters of that increase taking place between 1993 and 1999.

The relatively faster service delivery in the first 6 years of the 11 year period under consideration (1993 to 1999) is surprising given government's shift to a more expansionary fiscal policy and increased spending on service delivery post-2000. There are three possible explanations for this observed non-linearity in the growth of access to assets and services. Firstly, it needs to be remembered that the growth in access to services started from a relatively low base and that government's service delivery drive probably had a relatively rapid initial impact, especially in poor urban areas. Secondly, the post1999 period may reflect ongoing and possibly growing capacity and efficiency problems at a provincial and local government level, were the responsibility for housing delivery (provinces) and basic service delivery (local government) lies. Finally, the slowdown may 
reflect the continued existence of backlogs in deep rural areas, which are often not only the most difficult to reach, but also usually the last to be affected by pro-poor delivery.

\section{The Backlog Factor}

The figures above have clearly illustrated that the growth in government service delivery between 1993 and 2004 benefited the poor specifically. In all cases the growth in access rates was relatively pro-poor, with the bottom four household expenditure deciles in all cases experiencing increases in their access rates to government services, which were above the mean for all households.

There is, however, an important issue that has to be considered in order to complete our review of government service delivery over the first ten years of our democracy. Even though the poorest households clearly benefited most in terms of the growth in their access rates, very large numbers of poor households are still without basic services. In this regard we need to address some of the bias that may be induced if we concentrate on growth rates only. Figure 6 shows these backlogs in access to government services as they stood in 2004. 
Figure 6: Service Delivery Backlogs

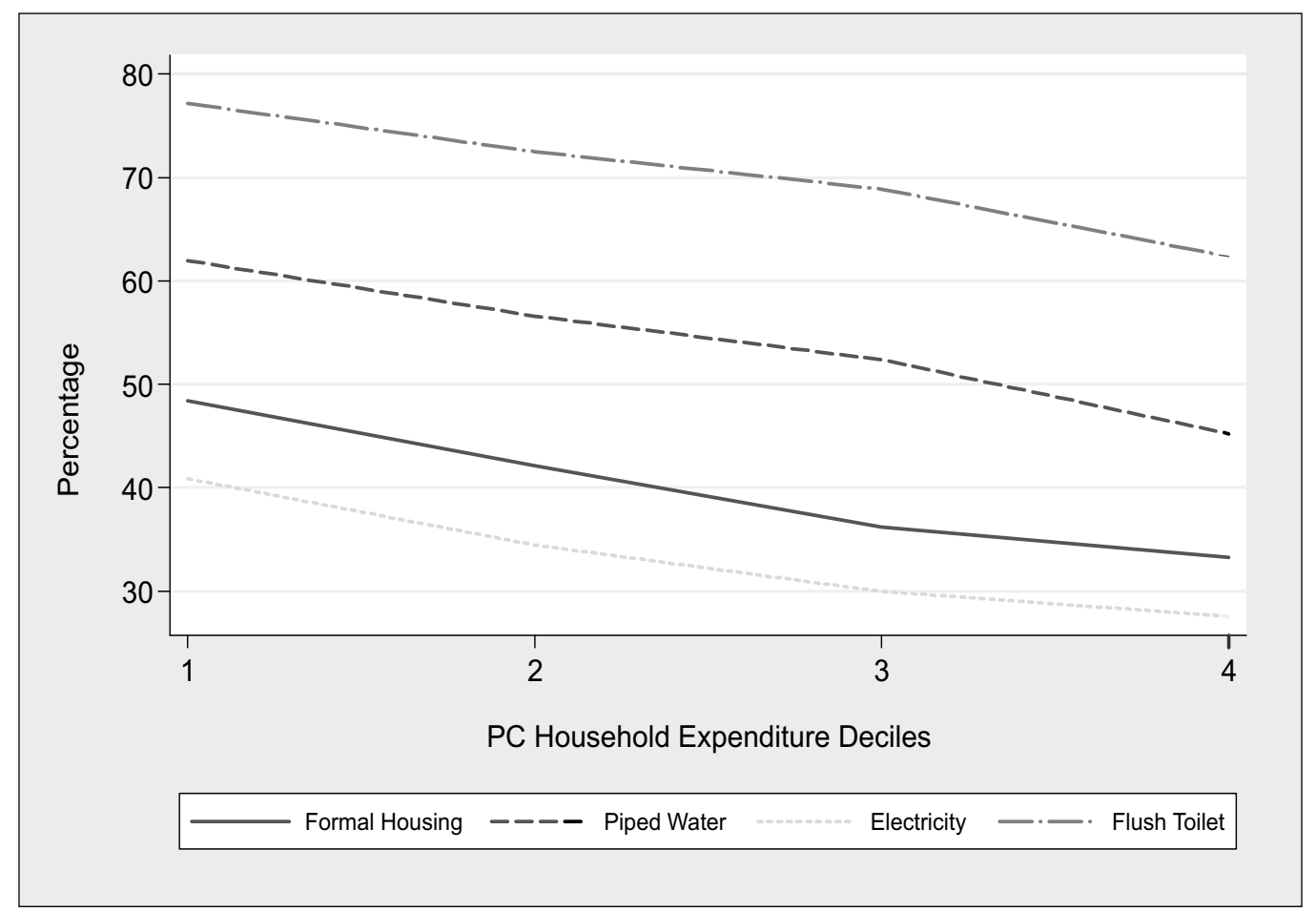

Source: GHS 2004 (Statistics SA); Own Calculations

In 2004, almost 80 per cent of the households in the poorest expenditure decile still did not have access to a flush/chemical toilet. This declined to just over 60 per cent for households in the fourth decile, but on average more than 70 per cent of the households in the bottom four expenditure deciles did not have access to a flush or chemical toilet. This backlog in the poorest deciles is almost double the aggregate backlog of 44 per cent. Despite the impressive growth in access to piped water, more than 60 per cent of households in the bottom expenditure decile did not have access to piped water in 2004, while on average more than half of the households in the poorest four deciles did not have access to piped water. Thirty-three per cent of all households did not have access to piped water in 2004. 
Almost half of the households in the first decile did not have access to formal housing in 2004 , declining to 33 per cent in the fourth decile. The aggregate backlog is only about 27 per cent. It appears that electricity delivery has been the relative success story, as on average just over a third of households in the poorest four deciles did not use electricity for lighting in 2004. ${ }^{5}$ But, still more than 40 per cent of the households in the bottom decile did not use electricity for lighting in 2004 and again this was almost double the aggregate backlog in the use of electricity for lighting.

Ultimately then, on the basis of the above descriptive overview, it is evident that government asset and service delivery in the 1993-2004 period was strongly pro-poor in nature. This holds true across all assets and services, with the increases in service delivery pro-poor in both relative and absolute terms. The results, therefore, reflect a state heavily biasing its delivery toward those at the bottom-end of the expenditure distribution. The increase in electricity delivery (as reflected by the increase in use of electricity for lighting) was by far the fastest, followed by piped water, with the delivery of formal housing relatively tepid in comparison. When the access rates for the three years were compared, evidence of non-linearity in the pace of service delivery emerged. Access to government services improved at a much faster rate between 1993 and 1999 than between 1999 and 2004. This issue becomes more critical when the backlogs that still exist are considered. Large proportions of poor households still do not have access to basic services, with the backlogs in access to flush/chemical toilets and piped water particularly large in the bottom expenditure deciles.

In the following section we briefly describe the factor analysis methodology used in the derivation of an asset index as an alternative measure of non-income welfare, before moving on to a short discussion of the results from our factor analysis.

$5 \quad$ As we do not have electricity access rates, the use of electricity for lighting is used as proxy for access to electricity and therefore households who did not use electricity for lighting in 2004 are regarded as households without access to electricity. 


\section{Derivation of the Asset Index}

The analysis of income poverty and inequality offers one significant advantage, in that measures of its variability (over time and over sub-groups), are undertaken with a common unit of measurement. The latter, as is common practice, are often consumptionor expenditure-based measures of household income. In contrast, however, attempts to measure non-income poverty and inequality - typically through the assets owned and services received by households - do not offer this advantage. Households' access to water and sanitation, the quality of their dwelling and so on, while all reflections of non-income welfare, are not easily amenable to a common metric. Within this context then, and in an attempt to provide some concentrated metric of non-income poverty and inequality shifts in the 1993-2004 period, we have elected to utilise the unique properties contained in a procedure known as factor analysis. ${ }^{6}$ After providing a brief methodological overview, we report a series of relevant estimates derived from our factor analysis - all of which ultimately inform our derivation of appropriate measures of non-income poverty and inequality.

\subsection{Factor Analysis Methodology}

We assume that our underlying model takes the following form, following Sahn \& Stifel (2000):

$$
a_{i k}=\beta_{k} c_{i}+u_{i k}
$$

where the ith household's ownership (represented by the variable $a_{i k}$ ) of asset or service, $k$, is linearly related to a common factor, $c_{i}$ which we term household welfare. The strength of the relationship is thus represented by the estimated value of $\beta$. The difficulty with the above, is that the independent variable $\left(c_{j}\right)$ and its coefficient $(\beta)$ are unobservable. However, the use of factor analysis allows us to directly estimate this relationship, and then to construct the appropriate weights for the household asset and service index.

6 Many researchers have utilised this or a similar approach. Sahn \& Stifel (2000) employed factor analysis to construct an asset index as an alternative measure of welfare/poverty and used it to compare poverty in 11 African countries over time and across countries, using data from the Demographic and Health Surveys. Filmer and Pritchett (2001) used a very similar approach, principal component analysis, to construct an asset index as proxy for household wealth. The World Bank (2000, 2004) uses the Filmer and Pritchett methodology to calculate household wealth in their Country Reports on Health, Nutrition and Population Conditions among Poor and Better-off Countries. The methodology has also been utilised by Booysen (2002) and Booysen, et. al (2004) as well as McKenzie (2003). It is important to note that the asset indices constructed by these researches include household durables as well as household characteristics/services. While the resulting index is generally referred to as an asset index, it thus includes more than just the durable assets. In keeping with other researchers, when we refer to assets in this report, unless otherwise specified, it includes household durables, certain household characteristics and access to services. 
Specifically, factor analysis proceeds from the assumption that the relationships between the variables under consideration (in our conception here, assets and services) are reducible to a square correlation matrix. In vector form, therefore, and drawing on the notation of equation (1), the correlation matrix takes the form $\mathbf{a}_{i k}$ which effectively represents the unique correlations between the $k$ assets and services across the $i$ households. Factor analysis involves trying to distil these correlations into (in our case here) one unique, common factor, which we can term $\boldsymbol{f}_{1 i}$. The values contained in this matrix are commonly referred to as factor loadings for the first (and in our case here, only) common factor. Technically, deriving these factor loadings on the unique factor are achieved through extracting the maximum possible variance that exists across the assets and service variables. This involves estimating both the unit roots of the correlation matrix (known as eigen values) and their eigen vectors (Child, 1969; Cattell, 1965). More importantly, though, these factor loadings serve as the starting point for constructing or effectively, imputing, our asset index. Put differently, given that we cannot impose a weighting structure on the different assets and services, in their contribution to overall household welfare, we estimate these weights. Through the process of factor analysis therefore, we are able to impute an appropriate and acceptable weighting structure for each specific asset or service available to households. Hence, we utilise the information from the unique factor loadings to derive:

$$
c_{i}=f_{1} a_{11}+f_{2} a_{22}+\ldots \ldots+f_{k} a_{i k}
$$

Where the values $f_{1}, \ldots f_{k}$ represent the weights being projected onto the observed assets owned and services received by households (Sahn \& Stifel, 2000). These values are often referred to as scoring coefficients in the applied literature. These scoring coefficients are then normalised for each household, in order to derive an asset index for each household. The normalisation is around the mean and standard deviation for each asset. Hence, our asset index is constructed as follows:

$$
A_{i}=f_{1}\left(\frac{a_{i 1}-\mu_{1}}{s_{1}}\right)+\ldots \ldots \ldots . .+f_{k}\left(\frac{a_{i k}-\mu_{k}}{s_{k}}\right)
$$

Where $\mu$ and $s$ represent the mean and standard deviation for each given asset or service respectively. Households that have low index scores will be deemed to be asset poor and those with high asset index values will generally be relatively well off in terms of access to services and asset ownership. On the basis of equation (3), we have the core information required to understand the nature and extent of shifts in non-income welfare in the postapartheid period. 


\subsection{Factor Analysis Results}

Two categories of variables were used in the construction of our asset index, namely household characteristics (or services) and household assets. The household characteristics (services) variables are type of dwelling (formal or traditional); type of roof (thatch, tile or corrugated); low quality wall material; source of water (piped, public and surface); source of energy for lighting (electricity, paraffin or candle); source of energy for cooking (electricity, paraffin or wood) and type of toilet facilities (flush/chemical, pit or none). The household assets included in the factor analysis are telecommunications (including both cellular phones and land line telephones), vehicles and televisions. ${ }^{7}$ All variables are binary with a value of 1 (if the household has access to it) or 0 (if the household does not have access to it).

The three datasets $(1993,1999$ and 2004$)$ were pooled and factor analysis was performed on the pooled sample. ${ }^{8}$ Table 1 presents the scoring coefficients (asset weights) for the asset index produced by our factor analysis, which are based on equation (2) above. as source of water, type of toilet (pit VIP or bucket) and radio. In this regard, Child's methodology of retaining factors with loadings more than 0.3 was followed (Child, 1969:45).

A set of weights was derived for the pooled sample to enable us to compare asset ownership across the three years. The weights on the asset variables which explain most of the variation among households in 1993 may differ from the weights on the asset variables which explain most of the variation among households in the other two years. For example, if relatively few households owned a phone in 1993 compared to 1999 and 2004, factor analysis performed on the 1993 data will put relatively more weight on ownership of a phone, compared to the weights when factor analysis is performed on the other two years. When factor analysis is performed on the pooled dataset, the weights will reflect the variation across all three years. For a more detailed discussion, see Appendix C. 
Table 1: Scoring Coefficients (Asset Weights) for Asset Index

\begin{tabular}{|l|r|l|r|}
\hline Asset & Weight & Asset & Weight \\
\hline formal & 0.06481 & candle_lig & -0.06757 \\
\hline traditional & -0.04873 & elect_cook & 0.18298 \\
\hline thatch_roof & -0.03237 & para_cook & -0.02883 \\
\hline tile_roof & 0.04367 & wood_cook & -0.0682 \\
\hline Corr_roof & -0.02905 & flush_chem & 0.16482 \\
\hline lowq_wall & -0.07024 & pit & -0.04895 \\
\hline piped & 0.14469 & no_toilet & -0.03843 \\
\hline public & -0.03985 & telecoms & 0.05917 \\
\hline surface & -0.03747 & vehicle & 0.04579 \\
\hline elect_lig & 0.13736 & TV & 0.06498 \\
\hline para_lig & -0.0298 & & \\
\hline
\end{tabular}

Source: PSLSD 1993 (SALDRU), OHS 1999 (Statistics SA), GHS 2004 (Statistics SA); Own Calculations

The signs of the weights are all as expected, with positive signs indicating assets of which ownership or access to, is associated with higher welfare. Relatively large positive weights were derived for access to piped water and use of electricity of lighting and cooking, as well as flush/chemical toilets.

The weights were applied to the three datasets and asset index values for all households across the three years were estimated. Table 2 provides the summary statistics for the asset index distribution for the three years.

Table 2: Mean Values for the Asset Index $\left(f_{1}\right), 1993,1999$ and 2004

\begin{tabular}{|l|c|c|}
\hline Year & Mean & t-statistic \\
\hline 1993 & -0.2393 & \\
\hline 1999 & -0.0169 & $-19.00^{*}$ \\
\hline 2004 & 0.1504 & $-21.30^{*}$ \\
\hline
\end{tabular}

Source: PSLSD 1993 (SALDRU), OHS 1999 (Statistics SA), GHS 2004 (Statistics SA); Own Calculations Notes: *Significant at the 5 per cent level

While it should be kept in mind that the actual value of the asset index is meaningless, in that it does not, for example, reflect any monetary value, the higher the value of the asset index of a household, the less "asset poor" that household is, as a relatively higher asset index value reflects a "basket" of household services and ownership of household assets which is indicative of a relatively (asset) wealthy household.

The mean values presented in Table 2 are the mean values of the asset index distribution in each of the three years. The fact that the mean value of the asset index increased across the three years means that the average household became less asset poor over the 
period. The initial evidence therefore indicates that the mean South African household's entitlement deprivation declined steadily over the first decade of democracy. The values of the t-statistics indicate that the change in the mean value of the asset index between 1993 and 1999, as well as between 1999 and 2004, is statistically significant.

Figure 7 compares the kernel density estimates of the asset index values for the three years across all households in the sample. In 1993, there is some clustering at the bottom as well as the top, indicating a concentration of households with relatively low asset values as well as a concentration of households at the top end. The apartheid backlog is particularly apparent with the 1993 data as indicated by the clumping at the lower end of the asset index distribution. The distribution changes quite dramatically over the period. The curve flattens at the bottom (lower value) end and the clustering increased over both periods at the upper-end. This illustrates how the proportion of households with an asset index value indicative of relative asset wealth increased over the period.

Figure 7: Distribution of Households according to Asset Index Value, 1993, 1999, 2004

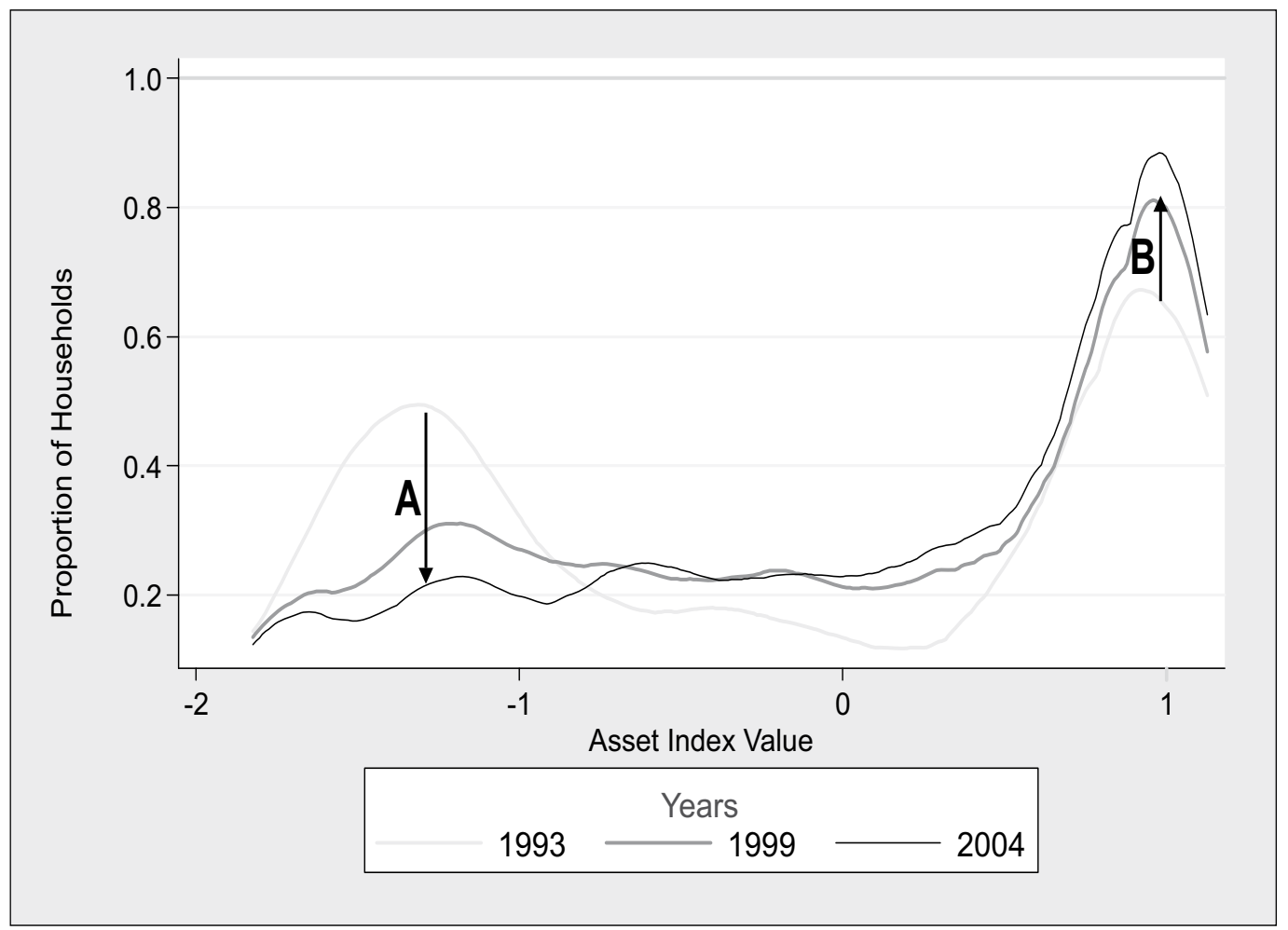

Source: PSLSD 1993 (SALDRU), OHS 1999 (Statistics SA), GHS 2004 (Statistics SA); Own Calculations 
The above reflects the success of government in improving access to assets and services at the bottom end of the distribution (A). Simultaneously, though, the increase in the accumulation of assets and services at the top-end $(B)$, is indicative possibly of the fruits of increased economic growth rather than state delivery. In other words, it reflects on the nature of the economic growth that took place over the period, possibly benefiting those at the top-end of the distribution disproportionately more than those households at the bottom.

While it is not possible to directly test that the long-run wealth of households explains the maximum variance in asset ownership, the asset index can be evaluated according to a number of tests to see if the factor analysis methodology has produced reasonable results. Filmer and Pritchett (2001: 117-119) have identified three "tests" which can be applied to the derived asset index to evaluate how reliable it is.

The first test evaluates the internal coherence of the asset index. This means that the averages asset ownership should differ significantly across poor, middle-income and rich households (as classified according to the asset index). The second test evaluates the robustness of the asset index. An asset index is robust if it produces similar classifications of households across different asset indices based on the inclusion of different variables. Thirdly, an asset index can be evaluated by comparing it with other measures of wealth or poverty (Booysen, 2002: 63; Filmer \& Pritchett, 2001: 117). Our derived asset index performed well on all three test and the results and discussion thereof can be found in Appendix D.

In this section we described the factor analysis methodology we used to derive our asset index. Factor analysis was performed on the pooled dataset and the resulting weights were applied to the three datasets, and asset index values for all households across the three years were estimated. At first glance, the summary statistics for the three years indicated that the average household became less asset poor over the period, as the mean values of the asset index increased between 1993 and 1999 and again between 1999 and 2004. The comparison of the distribution of households according to their asset index values across the three years confirmed this, with the proportion of households with an asset index value indicative of relative asset wealth increasing over the period. Section 5.1 presents the results when a set of standard poverty measures is applied to our asset index. Section 5.2 presents asset inequality estimates. 


\section{Measures of Non-Income Vulnerability}

In this section we present the results derived when applying standard poverty and inequality measures to our asset index values in 1993, 1999 and 2004. These measures allow us to evaluate the extent to which households' non-income poverty has changed in the post-apartheid period, as well as how the distribution of assets and services has changed over the period. We first discuss the results from the application of a range of standard poverty measures, before moving on to the results from the application of the inequality measures.

\subsection{Changing Patterns of Non-Income Poverty}

Poverty lines were calculated using the distribution of the asset index in the first survey (1993). ${ }^{9}$ Because the weights are constant across the three years, the poverty lines derived from the first year were then applied to the second and third surveys (Sahn \& Stifel, 2000: 2126) (Also see Appendix C). We derived two different poverty lines, the value at the $20^{\text {th }}$ percentile of the asset index distribution in 1993 and the value of the $40^{\text {th }}$ percentile of the asset index distribution in 1993. On their own these asset poverty lines do not mean much, but rather serve as reference point to compare the 1999 and 2004 asset index distributions against. 
To measure the changes in asset poverty, we utilised the general class of poverty measures first proposed by Foster, Greer and Thorbecke (1984), widely known as the FGT measures of poverty. ${ }^{10}$ Table 3 presents the changes in national poverty levels as measured by the headcount index (HC) and the poverty gap (PG) between 1993, 1999 and 2004.

Table 3: Measures of Poverty, 1993, 1999, 2004

\begin{tabular}{|l|c|c|c|c|}
\hline & \multicolumn{2}{|c|}{ Poverty Line $\mathbf{2 0}^{\text {th }}$ Percentile } & \multicolumn{2}{c|}{ Poverty Line $\mathbf{4 0}^{\text {th }}$ Percentile } \\
\hline & HC & PG & HC & PG \\
\hline $\mathbf{1 9 9 3}$ & $20.3 \%$ & $6.2 \%$ & $40.0 \%$ & $18.2 \%$ \\
\hline $\mathbf{1 9 9 9}$ & $12.0 \%^{*}$ & $4.6 \%$ & $28.5 \%^{*}$ & $12.0 \%$ \\
\hline $\mathbf{2 0 0 4}$ & $9.7 \%^{* *}$ & $4.0 \%$ & $21.6 \%^{* *}$ & $9.5 \%$ \\
\hline
\end{tabular}

Source: PSLSD 1993 (SALDRU), OHS 1999 (Statistics SA), GHS 2004 (Statistics SA); Own Calculations

Notes: * $\quad$ Change in the headcount poverty rate between 1993 and 1999 is statistically significant at the 5 per cent level. tstatistics were calculated using the method developed by Ravallion (1994: 57,58).

${ }^{* \star}$ Change in the headcount poverty rate between 1999 and 2004 is statistically significant at the 5 per cent level. $t$-statistics were calculated using the method developed by Ravallion (1994: 57,58).

Given that the asset index values at the $20^{\text {th }}$ percentile and $40^{\text {th }}$ percentile respectively in 1993 were used to calculate "reference" poverty lines, the two headcount asset poverty ratios were 40 per cent and 20 per cent respectively in 1993. According to the $40^{\text {th }}$ percentile headcount rate, asset poverty almost halved between 1993 and 2004, from 40 per cent to 21,6 per cent. The bulk of this decline took place between 1993 and 1999, when the headcount rate dropped by 11,5 percentage points. When the $20^{\text {th }}$ percentile

$10 \quad$ The FGT index of poverty measures can be represented in general form as:

$$
P_{\alpha}=\frac{1}{n} \sum_{i=1}^{n}\left(\frac{z-y_{i}}{z}\right)^{\alpha} \mid\left(y_{i} \leq z\right)
$$

Where $n$ is the total sample size, $z$ the chosen poverty line and $y_{i}$ is the standard of living indicator of agent $i$. The parameter measures how sensitive the index is to transfers between the poor units. The index is conditional on the agent's income, $y_{i}$, being below the poverty line, $z$. The headcount index is generated when $\alpha=0$, and then the above equation is simply the share of agents below the poverty line.

The poverty gap measure (PG) is generated when $\alpha=1$, and therefore the given poverty line $z$ is presented as

$$
P_{\alpha}=\frac{1}{n} \sum_{i=1}^{n}\left(\frac{z-y_{i}}{z}\right)\left(y_{i} \leq z\right)
$$

The PG represents a direct measure of agents' income (or in our case assets) relative to the poverty line (Bhorat \& Shaikh, 2004:14). 
asset poverty line is utilised a similar pattern is evident, with the headcount rate declining by more than 50 per cent (or 10,6 percentage points) between 1993 and 2004. Again, most of the decrease (8,3 percentage points) took place in the first period between 1993 and 1999. All the changes in the headcount poverty rates were statistically significant.

The poverty gap indicates the depth of asset poverty among the poor, by measuring the average distance a poor household is from the asset poverty line. In 1993, the average poor household's shortfall was 18,2 per cent below the $40^{\text {th }}$ percentile asset poverty line. This gap was almost halved to 9,5 per cent below in 2004 , indicating that the average poor household's shortfall decreased by almost nine percentage points. Again, much of the progress took place in the first half of the 1993-2004 period. When the $20^{\text {th }}$ percentile poverty line is used, the poverty gap declined from 6,2 per cent below the poverty line in 1993 to 4 per cent below the poverty line in 2004.

Race, location and gender can all be considered markers of vulnerability in the South African context. In Table 4 we present the changes in poverty levels according to the four race groups.

Table 4: Measures of Poverty by Race, 1993, 1999 and 2004

\begin{tabular}{|l|c|c|c|c|}
\hline & \multicolumn{2}{|c|}{ Poverty Line $\mathbf{2 0}^{\text {th }}$ Percentile } & \multicolumn{2}{c|}{ Poverty Line $\mathbf{4 0}^{\text {th }}$ Percentile } \\
\hline & $\mathrm{HC}$ & $\mathrm{PG}$ & $\mathrm{HC}$ & PG \\
\hline $\mathbf{1 9 9 3}$ & & & & $25.5 \%$ \\
\hline African & $28.5 \%$ & $8.7 \%$ & $55.6 \%$ & $0.7 \%$ \\
\hline Coloured & $0.1 \%$ & $0.0 \%$ & $3.7 \%$ & $0.0 \%$ \\
\hline Asian & $0.0 \%$ & $0.0 \%$ & $0.0 \%$ & $0.0 \%$ \\
\hline White & $0.0 \%$ & $0.0 \%$ & $0.1 \%$ & \\
\hline $\mathbf{1 9 9 9}$ & & & & $15.9 \%$ \\
\hline African & $16.0 \%^{*}$ & $6.1 \%$ & $37.4 \%^{*}$ & $2.3 \%$ \\
\hline Coloured & $1.7 \%^{*}$ & $0.4 \%$ & $7.4 \%^{*}$ & $0.1 \%$ \\
\hline Asian & $0.0 \%$ & $0.0 \%$ & $1.0 \%$ & $0.0 \%$ \\
\hline White & $0.0 \%$ & $0.0 \%$ & $0.5 \%^{*}$ & \\
\hline $\mathbf{2 0 0 4}$ & & & & $12.2 \%$ \\
\hline African & $12.6 \% \%^{* *}$ & $5.2 \%$ & $27.7 \%^{* *}$ & $1.5 \%$ \\
\hline Coloured & $1.0 \%^{* *}$ & $0.1 \%$ & $5.4 \%^{* *}$ & $0.0 \%$ \\
\hline Asian & $0.0 \%$ & $0.0 \%$ & $0.2 \%$ & $0.0 \%$ \\
\hline White & $0.0 \%$ & $0.0 \%$ & $0.1 \%^{* *}$ & \\
\hline
\end{tabular}

Source: PSLSD 1993 (SALDRU), OHS 1999 (Statistics SA), GHS 2004 (Statistics SA); Own Calculations

Notes: $\quad$ * Change in the headcount poverty rate between 1993 and 1999 is statistically significant at the 5 per cent level. t-statistics were calculated using the method developed by Ravallion (1994: 57,58).

** Change in the headcount poverty rate between 1999 and 2004 is statistically significant at the 5 per cent level. t-statistics were calculated using the method developed by Ravallion (1994: 57,58). 
Table 4 shows Africans had the highest headcount asset poverty rates across all three years and according to both poverty lines. In fact, the breakdown of poverty shares by race (see Appendix $\mathrm{E}$ ) shows that when the $40^{\text {th }}$ percentile poverty line is used, more than 99 per cent of asset poor households in 1993 were African. This declined marginally to 98 per cent in 2004 . When the $20^{\text {th }}$ percentile poverty line is used, African households accounted for 99,9 per cent of asset poor households in 1993, while in 2004 this share was still more than 99 per cent. Asset poverty therefore remains concentrated largely amongst African households.

The African population group did, however, benefit considerably from the aggregate decrease in asset poverty over the period. While the asset headcount rate for Africans according to the $40^{\text {th }}$ percentile asset poverty line was above the 40 per cent level at 55,6 per cent in 1993, it more than halved to 27,7 per cent in 2004. Matching the performance of the national headcount poverty rate, two-thirds of the decline (almost 20 percentage points) took place between 1993 and 1999, followed by another 10 percentage points decreased between 1999 and 2004. The average poor African household had a poverty gap of almost 26 per cent at the $40^{\text {th }}$ percentile poverty line in 1993 . This meant that the average poor African household was positioned almost 26 per cent below the asset poverty line. This shortfall below the poverty line decreased by more than 50 per cent to 12,2 per cent in 2004, with the initial decrease of 12,5 percentage points between 1993 and 1999 accounting for most of the improvement in the poverty gap over the period as a whole.

African asset poverty headcount rates as well as the poverty gap followed a similar pattern when poverty was measured according to the $20^{\text {th }}$ percentile. About 80 per cent of the decline in the headcount rate from 28,5 per cent to 12,6 per cent took place between 1993 and 2004. The change in the poverty gap indicates that the average asset poor African household position below the $20^{\text {th }}$ percentile asset poverty line improved by 3,5 percentage points to 5,2 per cent in 2004 , with two-thirds of the progress taking place between 1993 and 1999. Again, the changes in the headcount rates according to both poverty lines were statistically significant.

Coloured poverty rates followed a peculiar pattern, with the asset poverty headcount rate according to the $40^{\text {th }}$ percentile poverty line increasing from 3,7 per cent to 7,4 per cent, and then declining to 5,4 per cent in 2004. This implies that Coloured households became more asset poor between 1993 and 1999 and that the increase in service delivery between 1999 and 2004 only marginally succeeded in correcting this. Closer inspection of the data revealed that the Coloured access rates to a number of services and assets (including formal dwelling, piped water, flushed/chemical toilet and vehicle ownership) declined between 1993 and 1999, and for the most part picked up again between 1999 
and 2004. In terms of actual numbers, the number of Coloured households with access to the range of services and assets increased significantly between 1993 and 2004. In other words, the actual number of asset poor Coloured households declined over the period. All changes in the headcount poverty rates for Coloured households were statistically significant. Although the headcount rate according to the $20^{\text {th }}$ percentile poverty line did change over the period, the absolute number of poor Coloured households at that poverty line remained relatively small.

Table 5 presents asset poverty measures by location. Although asset poverty declined according to both poverty lines both in urban and rural areas between 1993 and 2004, asset poverty remained much more severe in rural than in urban areas (See Appendix $F$ for the asset poverty shares by location). (The results of the t-statistics indicate that all the changes in the headcount poverty rates were statistically significant.)

Table 5: Measures of Asset Poverty by Location, 1993, 1999 and 2004

\begin{tabular}{|l|r|r|r|r|}
\hline & \multicolumn{2}{|c|}{ Poverty Line 20 } & \multicolumn{2}{c|}{ Poverty Line $\mathbf{4 0}^{\text {th }}$ Percentile } \\
\hline & HC & \multicolumn{1}{|c|}{ PG } & HC & PG \\
\hline $\mathbf{1 9 9 3}$ & & & & \\
\hline Rural & $38.4 \%$ & $12.6 \%$ & $72.7 \%$ & $34.2 \%$ \\
\hline Urban & $4.5 \%$ & $0.6 \%$ & $11.2 \%$ & $4.1 \%$ \\
\hline $\mathbf{1 9 9 9}$ & & & & $25.2 \%$ \\
\hline Rural & $25.7 \%^{*}$ & $10.8 \%$ & $56.5 \%^{*}$ & $3.3 \%$ \\
\hline Urban & $3.1 \%^{*}$ & $0.5 \%$ & $10.0 \%^{*}$ & $19.6 \%$ \\
\hline $\mathbf{2 0 0 4}$ & & & & $2.4 \%$ \\
\hline Rural & $20.0 \%^{* *}$ & $9.0 \%$ & $43.2 \%^{* *}$ & $6.7 \%^{* *}$ \\
\hline Urban & $2.6 \%^{* *}$ & $0.5 \%$ & & \\
\hline
\end{tabular}

Source: $\quad$ PSLSD 1993 (SALDRU), OHS 1999 (Statistics SA), GHS 2004 (Statistics SA); Own Calculations

Notes: $\quad$ * Change in the headcount poverty rate between 1999 and 1993 is statistically significant at the 5 per cent level.

t-statistics were calculated using the method developed by Ravallion (1994: 57,58).

${ }^{*}$ Change in the headcount poverty rate between 2004 and 1999 is statistically significant at the

5 per cent level. $t$-statistics were calculated using the method developed by Ravallion (1994: 57,58).

Measured according to the $40^{\text {th }}$ percentile poverty line, almost three-quarters of rural households were asset poor in 1993. This declined to about 43 per cent in 2004, with more than 50 per cent of the decrease in rural asset poverty taking place between 1993 and 1999. However, the fact that more than 40 per cent of rural households were still asset poor in 2004 means that headcount asset poverty rate for rural households was higher in 2004 than the aggregated headcount rate in 1993.

Urban asset poverty according to the $40^{\text {th }}$ percentile was already very low at 11,2 per cent in 1993 . This declined by only about one percentage point to 10 per cent in 1999 and by 
a further 3,3 percentage points to 6,7 per cent in 2004 . While the rates are very low, the trend is markedly different from those observed at national level and for African and rural households. Urban asset poverty declined at a faster rate in the second period between 1999 and 2004, in contrast to the faster decline between 1993 and 1999 observed at national level and for African and rural households.

The asset poverty gap for rural households at the $40^{\text {th }}$ percentile decreased from 34 per cent in 1993 to just below 20 per cent in 2004, indicating that the average poor rural household saw its distance from the asset poverty line decline by 14 percentage points.

Asset poverty levels according to the $20^{\text {th }}$ percentile follow a similar pattern, with asset poverty much more severe in rural areas. The rural headcount rates did, however, decrease rapidly from 38,4 per cent in 1993 to almost 26 per cent in 1999 and further to 20 per cent in 2004.

Table 6 shows that in all three years and for both poverty lines, households headed by females had higher asset poverty rates than households headed by males. Both female and male headed households, however, experienced an almost 50 per cent decline in their headcount asset poverty rates according to the $40^{\text {th }}$ percentile between 1993 and 2004. Again, the poverty rates dropped at a faster rate between 1993 and 1999, than in the second period. Female headed households experienced a decline from 50 per cent in 1993 to about 29 per cent in 2004, while male headed households saw their poverty rate decrease from 36 per cent to 17,3 per cent. Al these changes were statistically significant. 
Table 6: Asset Poverty Measures by Gender of Household Head, 1993, 1999 and 2004

\begin{tabular}{|l|r|r|r|r|}
\hline & \multicolumn{2}{|c|}{ Poverty Line 20 } & \multicolumn{2}{c|}{ Poverty Line $\mathbf{4 0}^{\text {th }}$ Percentile } \\
\hline & HC & PG & HC & PG \\
\hline $\mathbf{1 9 9 3}$ & & & & $23.1 \%$ \\
\hline Female & $26.0 \%$ & $8.1 \%$ & $50.0 \%$ & $16.3 \%$ \\
\hline Male & $17.6 \%$ & $5.5 \%$ & $36.0 \%$ & $16.0 \%$ \\
\hline $\mathbf{1 9 9 9}$ & & & & $9.6 \%$ \\
\hline Female & $16.1 \%^{*}$ & $6.7 \%$ & $36.2 \%^{*}$ & \\
\hline Male & $9.4 \%^{*}$ & $3.3 \%$ & $23.8 \%^{*}$ & $13.1 \%$ \\
\hline $\mathbf{2 0 0 4}$ & & & & $7.3 \%$ \\
\hline Female & $13 . \%^{* *}$ & $5.9 \%$ & $28.9 \%^{* *}$ & \\
\hline Male & $7.3 \%^{* *}$ & $2.8 \%$ & $17.3 \%^{* *}$ & \\
\hline
\end{tabular}

Source: PSLSD 1993 (SALDRU), OHS 1999 (Statistics SA), GHS 2004 (Statistics SA); Own Calculations

Notes: * * Change in the headcount poverty rate between 1993 and 1999 is statistically significant at the 5 per cent level.

t-statistics were calculated using the method developed by Ravallion (1994: 57,58).

${ }^{*}$ Change in the headcount poverty rate between 1999 and 2004 is statistically significant at the 5 per cent level.

t-statistics were calculated using the method developed by Ravallion (1994: 57,58).

The declines in the poverty gap ratios for both groups indicate that the average household saw it position relative to the asset poverty line improve over the period. In 1993, the average poor household headed by a female was 23 per cent below the asset poverty line. This improved to 13 per cent in 2004. The average male headed poor household was 16,3 per cent below the asset poverty line in 1993 and this improved by nine percentage points to 7,3 per cent in 2004. In both cases the largest shares of the progress took place between 1993 and 1999.

Headcount rates measured according to the $20^{\text {th }}$ percentile poverty line, declined from 26 per cent in 1993 to 13,7 per cent in 2004 for female headed households and from 17,6 per cent in 1993 to 7,3 per cent in 2004 for households headed by males. Again, the bulk of the decline for both groups took place in the first period. In addition, at this poverty line, asset poverty for male headed households more than halved between 1993 and 2004, while female headed households experienced a less than 50 per cent drop in their headcount rates. Again, all the changes in the $20^{\text {th }}$ percentile headcount rates were statistically significant.

The above figures, however, mask two very important developments over the period. Appendix $\mathrm{J}$ presents the asset poverty shares according to the gender of the household head. In 1993 female headed households accounted for 35,4 per cent of asset poor households as measured according to the $40^{\text {th }}$ percentile asset poverty line. This proportion increased to 49,6 per cent in 2004, By 2004, therefore, asset poor households were almost equally divided according to the gender of the head. In fact, a closer examination of the figures revealed that according to the $40^{\text {th }}$ percentile poverty line, the absolute 
number of poor households headed by a female actually increased, from 1200723 in 1993 to 1307249 in 2004.

The same trend can be observed when considering the poverty shares calculated at the $20^{\text {th }}$ percentile poverty line. The female headed households increased their share of asset poor households from 36,7 per cent in 1993 to more than half $(52,4$ per cent) of the total number of asset poor households in 2004.

Over the same period, the share of female headed households in the total population increased from 28,3 per cent in 1993 to 37,1 per cent in 2004 (See Appendix K). When we compare this to the increase in the share of poor households, it is clear that female headed households saw their share in total poor households increase at a faster rate than their share in total households. These trends confirm the increased feminisation of poverty in South Africa (Bentley, 2004).

The analysis above has shown that although non-income poverty declined considerably over the period for the most vulnerable groups, namely African, rural and female headed households, asset poverty rates for these households still remained much higher in 2004 than for their less vulnerable counterparts. The question that now arises, relates to the position of the households that belong to more than one of these vulnerable groups and the extent to which these households have benefited from increased delivery of services and assets since 1994. Table 7 shows the poverty measures for rural African households and rural African households headed by females. Aggregate poverty measures are included to enable easy comparison. 
Table 7: Measures of Poverty 1993, 1999 and 2004

\begin{tabular}{|c|c|c|c|c|}
\hline & \multicolumn{2}{|c|}{ Poverty line 20th percentile } & \multicolumn{2}{|c|}{ Poverty line 40th percentile } \\
\hline & $\mathrm{HC}$ & PG & $\mathrm{HC}$ & PG \\
\hline \multicolumn{5}{|c|}{ Rural African Households } \\
\hline 1993 & $40.2 \%$ & $13.2 \%$ & $75.8 \%$ & $35.7 \%$ \\
\hline 1999 & $27.4 \%$ * & $11.5 \%$ & $59.8 \%$ * & $26.8 \%$ \\
\hline 2004 & $21.4 \%$ ** & $9.7 \%$ & $45.8 \%$ ** & $20.9 \%$ \\
\hline \multicolumn{5}{|c|}{ Rural African Female-Headed Households } \\
\hline 1993 & $47.7 \%$ & $15.5 \%$ & $86.7 \%$ & $41.6 \%$ \\
\hline 1999 & $31.2 \%$ * & $13.7 \%$ & $65.4 \%$ * & $30.3 \%$ \\
\hline 2004 & $25.5 \%$ ** & $11.8 \%$ & $53.4 \%$ ** & $24.6 \%$ \\
\hline \multicolumn{5}{|l|}{ All Households } \\
\hline 1993 & $20.3 \%$ & $6.2 \%$ & $40.0 \%$ & $18.2 \%$ \\
\hline 1999 & $12.0 \%$ * & $4.6 \%$ & $28.5 \%$ * & $12.0 \%$ \\
\hline 2004 & $9.7 \%$ ** & $4.0 \%$ & $21.6 \%$ ** & $9.5 \%$ \\
\hline
\end{tabular}

Source: PSLSD 1993 (SALDRU), OHS 1999 (Statistics SA), GHS 2004 (Statistics SA); Own Calculations

Notes: * * Change in the headcount poverty rate between 1993 and 1999 is statistically significant at the 5 per cent level. t-statistics were calculated using the method developed by Ravallion (1994: 57,58).

** Change in the headcount poverty rate between 1999 and 2004 is statistically significant at the 5 per cent level. t-statistics were calculated using the method developed by Ravallion (1994: 57,58).

In 1993, more than 75 per cent of rural African households were asset poor according to the 40th percentile asset poverty line. This headcount rate was higher than the rates for African households or rural households separately. The 40th percentile headcount rate for rural African households decreased by 30 percentage points, with just over 50 per cent of the decrease taking place between 1993 and 2004. However, almost 46 per cent of African rural households were still asset poor, which is more than double the aggregate headcount poverty rate according to the 40th percentile in 2004 . The poverty gap according to the 40th percentile also declined significantly over the period by almost 15 percentage points. However, the average rural African household was still almost 21 per cent below the 40th percentile poverty line in 2004, in contrast to the aggregate picture in 2004, where the average poor household was less than 10 per cent below the poverty line.

The headcount rate for rural African households according to the 20th percentile almost halved between 1993 and 2004. Again, however, at 21,4 per cent the headcount rate in 2004 was almost double the 20th percentile headcount rate at the aggregate level. In fact, in 2004 both the headcount rates for rural African households were still higher than the aggregates rates at the 20th and the 40th percentile in 1993. All the changes in the headcount asset poverty rates were statistically significant. 
The poverty measures for rural African households headed by females paint a bleak picture. Almost ninety per cent of these households were asset poor in 1993 according to the 40th percentile poverty line. This was more than double the aggregate headcount rate. Rural African female-headed households did benefit significantly from the increased delivery in assets and services, with a 33 percentage point decline between 1993 and 2004. Again the bulk of the decline took place between 1993 and 2004. However, in 2004 more than half of the African female headed households living in rural areas were still asset poor according to the 40th percentile poverty line. The poverty gap declined from 42 per cent to 24,5 per cent over the period. This means that the average poor African female headed household in a rural area was still almost 25 per cent below the 40th percentile poverty line in 2004. This is again in stark contrast to the average poor household at aggregate level that was about 10 per cent below the 40th percentile poverty line in 2004.

Poverty rates according to the 20th percentile followed a similar pattern. Almost half of African female headed households in rural areas were asset poor according to that poverty line in 1993. Although the rate almost halved to just over a quarter of these households in 2004, it was two and a half times the aggregate rate in 2004.

Two important points emerged from the above analysis. First, the asset poverty estimates showed that measured non-income poverty decreased across a range of covariates between 1993 and 2004, and that generally most of the decline took place between 1993 and 2004. Second, although non-income poverty declined considerably over the period for the most vulnerable groups, namely African, rural and female headed households, asset poverty rates for these households still remained much higher in 2004 than for their less vulnerable counterparts. When these households were investigated further, it was shown that female headed African households living in rural areas were particularly vulnerable. Although these households did witness a decrease in their poverty levels, more than half of African female headed households living in rural areas were still asset poor according to the 40th percentile in 2004. In 2004 more than a quarter of those households were still asset poor according to the 20th percentile poverty line. The fact that the 2004 headcount rates for these households were above the aggregate rates of 1993, emphasises the continued marginalisation of poor African women living in rural areas. 


\section{Non-Income Poverty without Poverty Lines}

Another way of examining the changing pattern of asset poverty is by graphing cumulative distribution functions (CDFs). In the case of the asset index, the vertical axis of the CDF shows the percentage of total households with an asset index value that is less than or equal to the asset index value on the horizontal axis. As the asset index value rises, the corresponding cumulative proportion of households will also rise. CDFs allow us to compare the changes in poverty between two time periods independent of any feasible poverty line. If a CDF for period $t+1$ lies at any point on the horizontal axis below the CDF for period $t$, it means that poverty has decreased between the two periods irrespective of any specific poverty line.

Figure 8 shows the CDF graphs for African households for 1993, 1999 and 2004.

Figure 8: Cumulative Distribution Functions for Africans, 1993, 1999, 2004

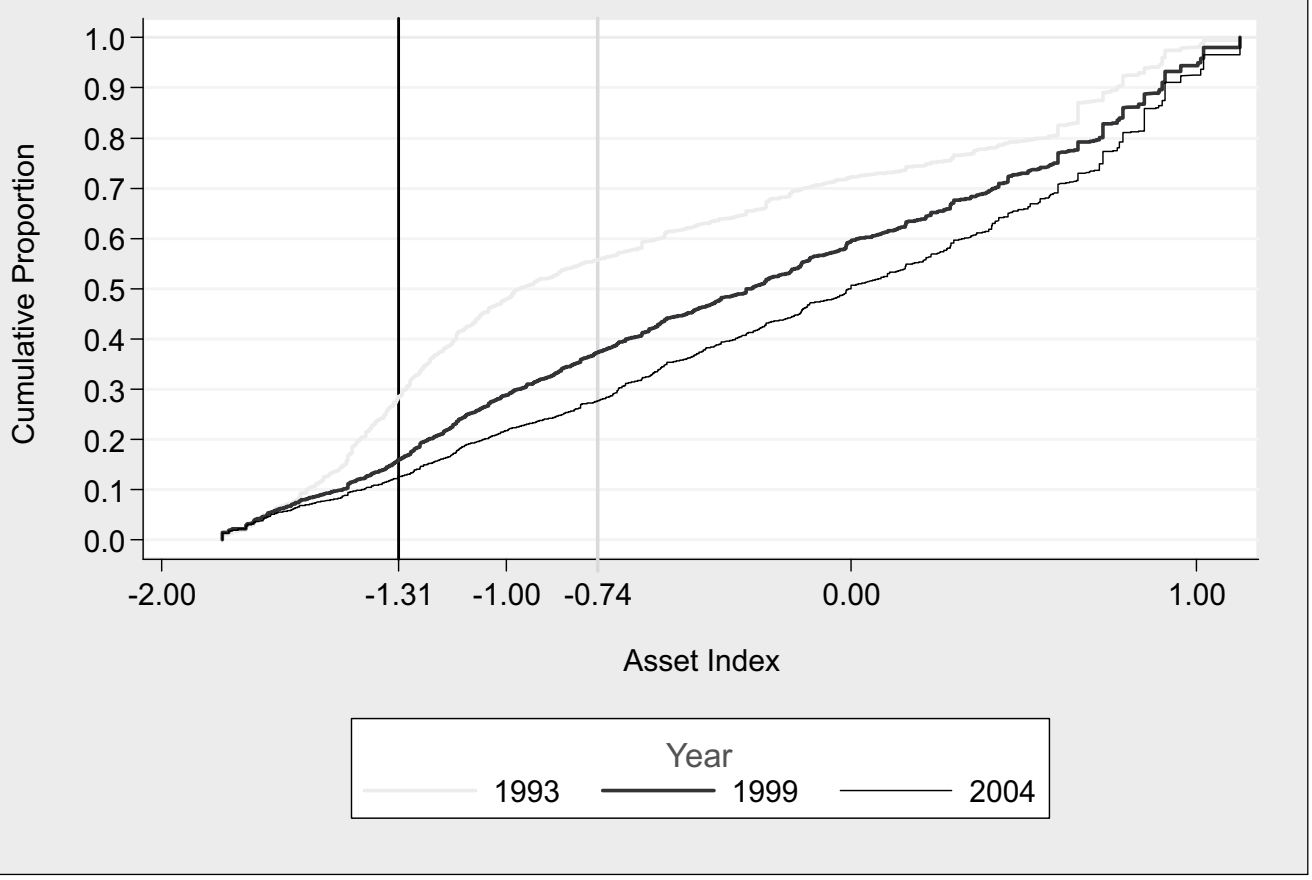

Source: PSLSD 1993 (SALDRU), OHS 1999 (Statistics SA), GHS 2004 (Statistics SA); Own Calculations

With the exception of roughly the bottom 10 per cent of households, the 1999 CDF graph lies below the 1993 CDF graph, while the 2004 CDF graph lies below the 1999 graph independent of any feasible poverty line. In the language of this literature, we can state 
that first-order dominance holds. This graphically confirms that asset poverty declined between 1993 and 1999, and decreased further between 1999 and 2004 irrespective of the poverty line chosen. In addition, the fact that the gap between the 1993 and 1999 CDFs is relatively wider than the gap between the 1999 and 2004 CDFs graphically confirms that the pace of delivery between 1993 and 1999 outstripped that between 1999 and 2004.

It appears as if the position of the bottom 10 per cent of African households in each year did not change. When African headcount rates according to a $10^{\text {th }}$ percentile poverty line were estimated, it was found that the headcount rate decreased from 14 per cent in 1993 to 10 per cent in 1999 and then declined marginally to 8,3 per cent in $2004 .{ }^{11}$ This decline was, however, relatively small in comparison to the decline in the African headcount rates according to the $20^{\text {th }}$ and $40^{\text {th }}$ percentiles, which more than halved over the same period. While the households at the bottom of the distribution did benefit from increased delivery of asset and services over the period, it was at a relatively slower rate.

Figure 9 presents the CDFs for rural households, with the CDFs for urban households in Appendix G. Although the rural and urban CDFs are not drawn on the same set of axes, it is still very clear that the rural CDFs lie above the urban CDFs for all three years, illustrating the relatively higher levels of rural asset poverty.

11 The national asset poverty headcount rate according to the $10^{\text {th }}$ percentile poverty line decreased from 10 per cent in 1993 to 7,4 per cent in 1999 and with another percentage point to 6,4 per cent in 2004. 
Figure 9: Cumulative Distribution Functions for Rural Households, 1993, 1999 and 2004
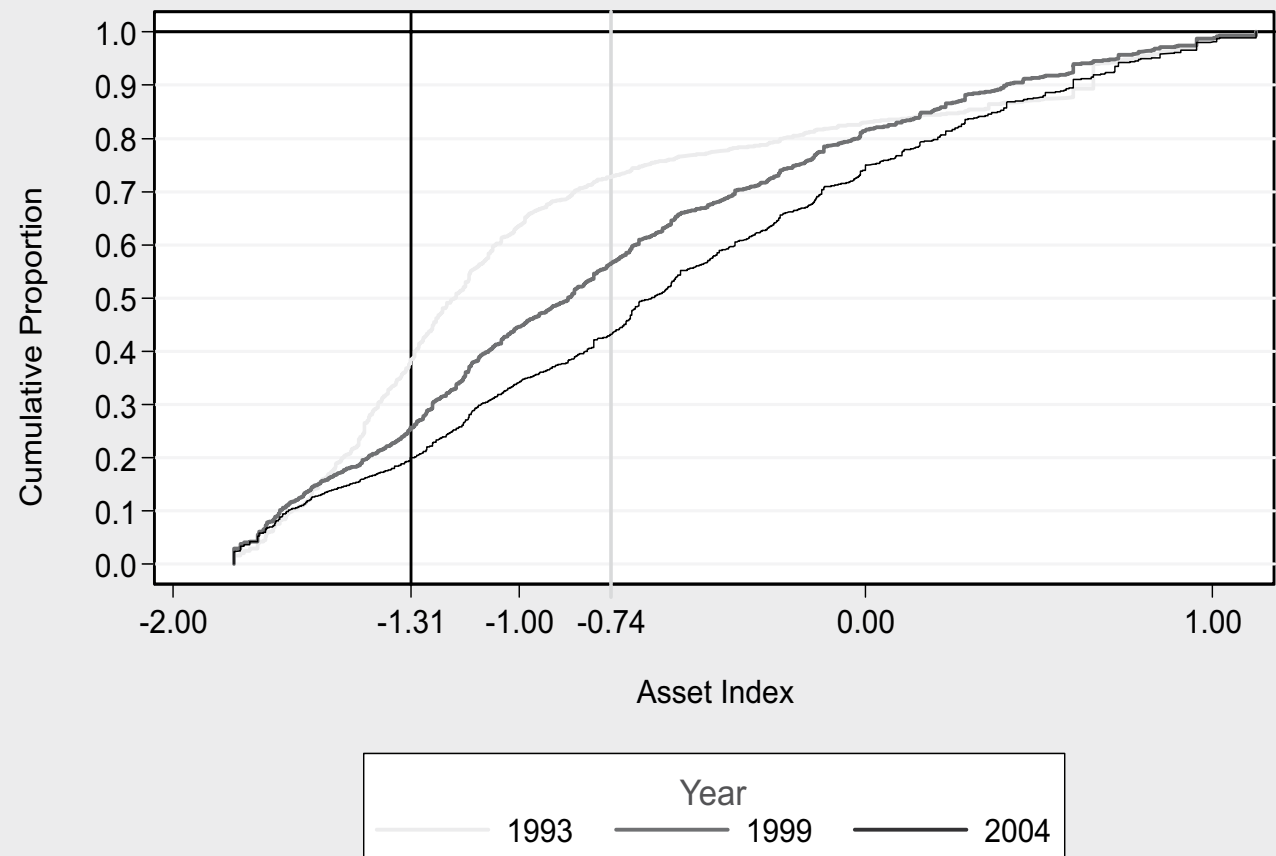

Source: PSLSD 1993 (SALDRU), OHS 1999 (Statistics SA), GHS 2004 (Statistics SA); Own Calculations

In the case of rural households, with the exception of the very bottom and the very top, the 2004 CDF lies below the 1993 and 1999 CDFs, illustrating the fact that irrespective of the poverty line chosen, non-income poverty in rural areas declined in the post-apartheid period. The relatively faster decline in poverty between 1993 and 1999 is also evident. Again, it appears as if the bottom approximately 10 per cent of households every year did not see their position improve. The change in rural headcount asset poverty rates according to the $10^{\text {th }}$ percentile poverty line, though, confirms that rural households at the bottom of the distribution did experience a decline in their asset poverty, from 21 per cent in 1993 to 15 per cent in 2004. This, however, remains more than double the aggregate $10^{\text {th }}$ percentile headcount rate, which declined to 6 per cent in 2004 . This does suggest that the very poor households in rural areas have been benefiting less from increased service delivery over the period. 
As expected, the urban CDFs (see Appendix $G$ ) show relatively small decreases in asset poverty over the period, with the 1999 graph lying slightly below the 1993 graph and the 2004 graph lying slightly below the 1999 graph.

Appendix F contains CDFs for all nine provinces across the three years. The two richest provinces in terms of income measures of poverty, the Western Cape and Gauteng (Leibbrandt, Poswell, Naidoo, Welch \& Woolard, 2005: 15-17), were also the two richest provinces according to our asset poverty measure. The two poorest provinces as measured by income poverty measures, the Eastern Cape and Limpopo (Leibbrandt, Poswell, Naidoo, Welch \& Woolard, 2005: 15-17) were also the poorest provinces according to our asset index.

In addition, the CDFs show that some of the poorer provinces (in terms of access to assets and services), experienced the largest decreases in asset poverty as illustrated by shifts in the CDFs. This is especially evident when looking at the Eastern Cape, Limpopo, Free State, North West and KwaZulu Natal. These are provinces with large rural areas and these changes also reflect the relatively larger decrease in asset poverty levels in rural areas as in urban areas.

The CDF graphs for female headed households in Figure 10 confirm that asset poverty for these households decreased over the period. Again the relatively larger gap between the 1993 and 1999 graphs illustrates that asset poverty declined at a faster rate in that period than between 1999 and 2004. 
Figure 10: Cumulative Distribution Functions for Female Heads of Households

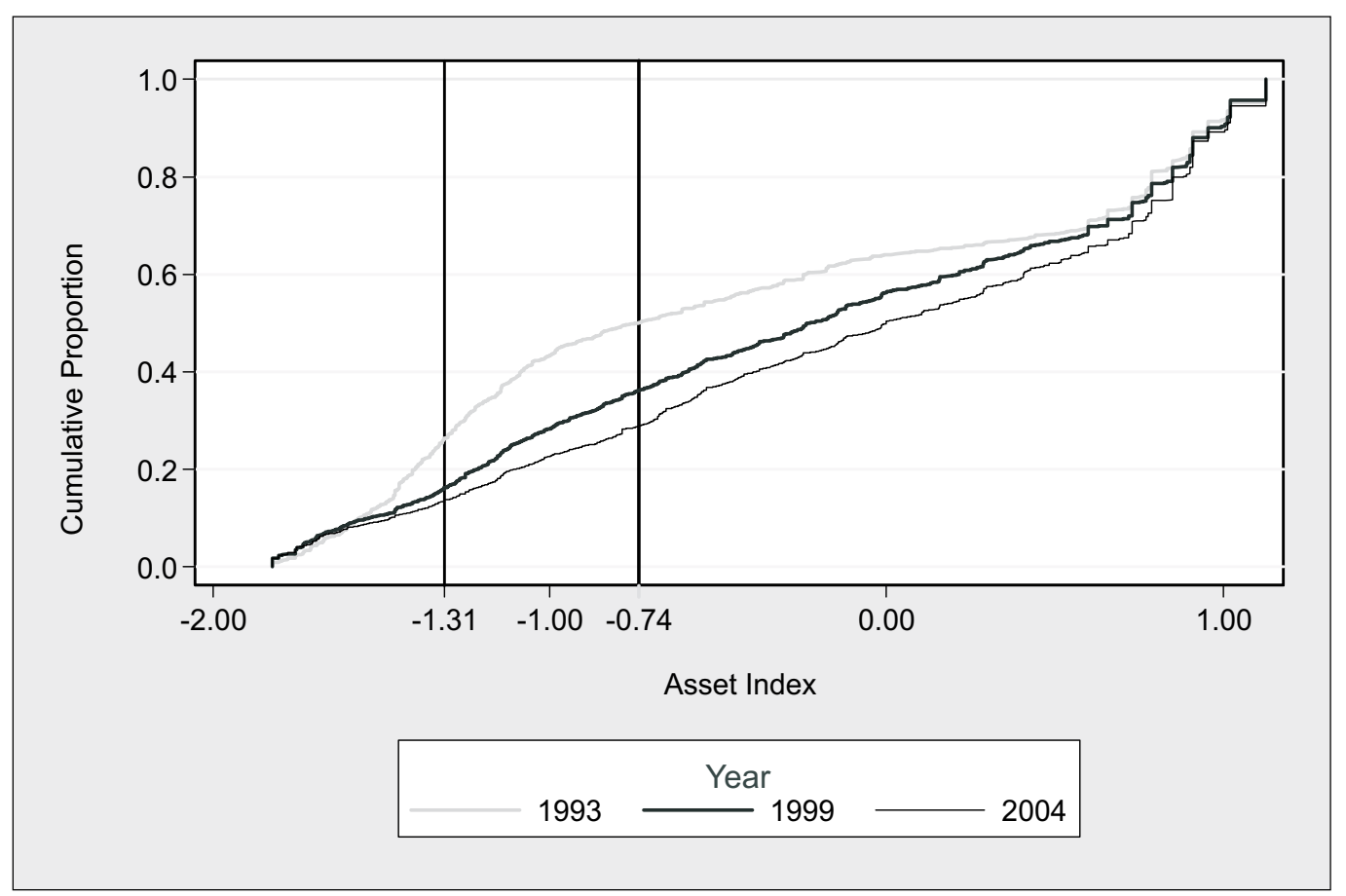

Source: PSLSD 1993 (SALDRU), OHS 1999 (Statistics SA), GHS 2004 (Statistics SA); Own Calculations

While graphically it appears as if the households at the bottom of the distribution did not experience any decrease in their asset poverty, the $10^{\text {th }}$ percentile asset poverty headcount rate for female headed households did decline marginally from 13 per cent in 1993 to 11 per cent in 1999 and further to 10 per cent in 2004.

The CDFs for rural African households in Appendix I show that irrespective of the poverty line utilised the asset poverty levels of African households in rural areas declined between 1993 and 1999 and between 1999 and 2004. Again the households at the bottom of the distribution did not experience large decreases in their asset poverty rates, illustrated by the fact that the $10^{\text {th }}$ percentile headcount rate only declined by 6 percentage points from 22 per cent in 1993 to 16 per cent in 2004 . This headcount rate in 2004 was more than two-and a half times the $10^{\text {th }}$ percentile headcount rate at the aggregate level.

Finally, the CDFs in Figure 11 confirm that African households in rural areas headed by females, in corroboration with much of the income poverty measures, face the highest levels of asset and service vulnerability. 
Figure 11: Cumulative Distribution Functions for Rural African Female-Headed Households, 1993, 1999, 2004

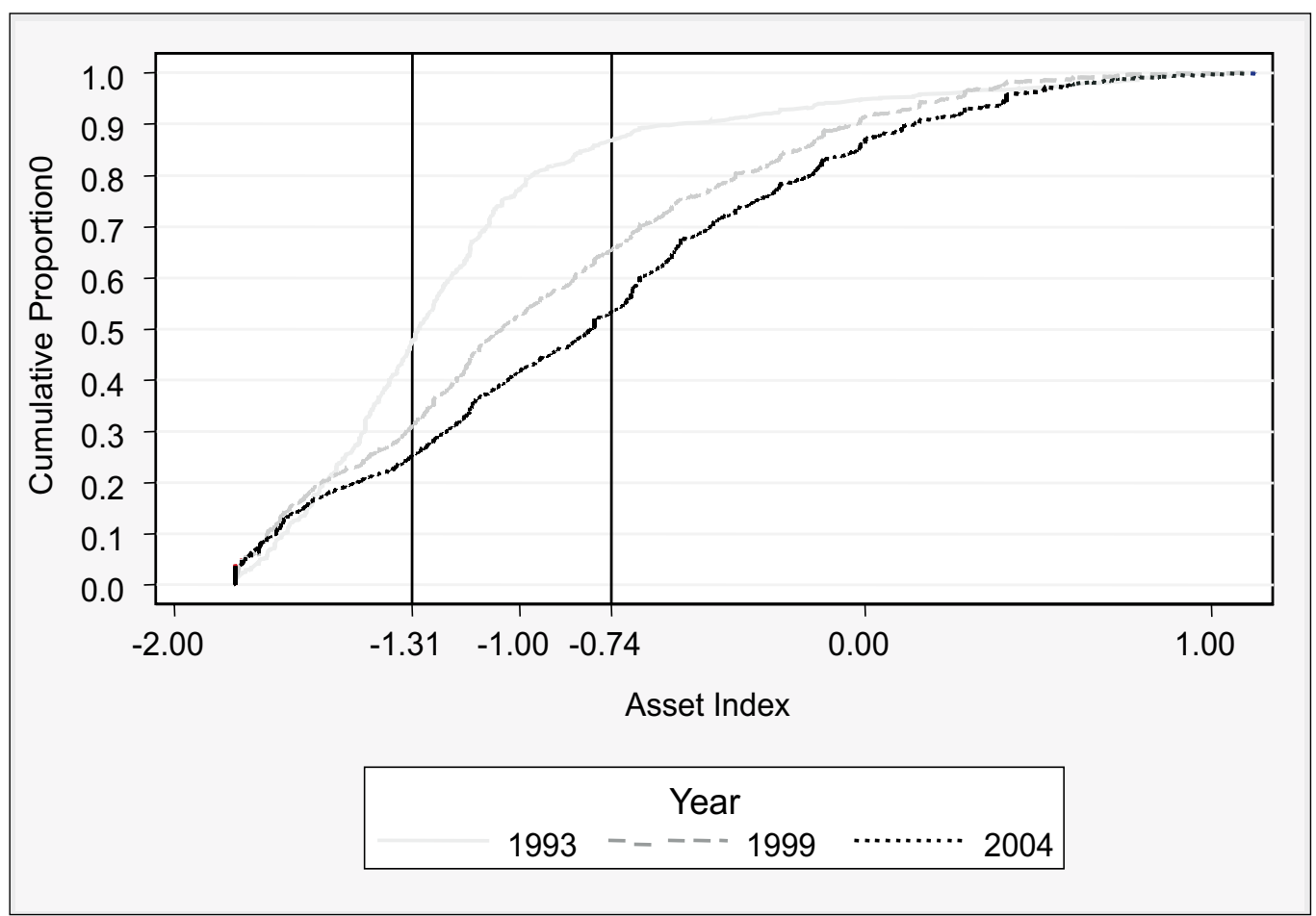

Source: PSLSD 1993 (SALDRU), OHS 1999 (Statistics SA), GHS 2004 (Statistics SA); Own Calculations

The 1999 CDF lies below the 1993 CDF and the 2004 CDF lies below the 1999 CDF for the most part, illustrating these households did witness a decline in their asset poverty levels between 1993 and 1999 and again between 1999 and 2004. The changes in the $10^{\text {th }}$ percentile headcount rates do show that even the rural African female-headed households at the bottom of the distribution benefited from increased asset and service delivery. These rates, however, remained very high in comparison with the aggregate level as well as other covariates. Rural African households headed by females had a $10^{\text {th }}$ percentile headcount rate of 26 per cent in 1993 . This declined marginally to $23 \%$ in 1999 and further to 20 per cent in 2004. These households therefore continue to be affected both by the increased feminisation of poverty (as discussed earlier in terms of the increase in female headed households' share in total poor households) and the fact that they may be living in rural areas which are proving very difficult to reach in terms of the delivery of basic services. 
The CDFs confirm that not only did non-income poverty decline for all covariates between 1993 and 2004, but that the decreases hold true across a range of feasible poverty lines. The relative position of the graphs for each covariate also illustrated that poverty decreased at a relatively faster rate between 1993 and 1999 relative to the 1999-2004 period. African households, headed by females and living in rural areas, displayed asset poverty rates (according to all asset poverty lines) in 2004 that were still above the aggregate rates of 1993. These CDFs graphically captured the fact that, despite decreases in their poverty levels according to all the standards measures reported here, African, rural and femaleheaded households remain particularly vulnerable.

\subsection{Measures of Asset Inequality}

In order to evaluate the changes in asset inequality, we applied a series of inequality measures to our asset index values in a manner identical to the previous section. South Africa's high Gini coefficient ${ }^{12}$ (calculated using income or expenditure data internationally) is by now a well-known feature of the economy. Researchers have shown that, using different datasets, inequality measured with income data, has increased in the 1990s, with the magnitude of the estimated Gini coefficient at a national level ranging from 0.68 in 1991 to $0.68 / 0.69$ in 1996 to 0.73 in 2001 (See Leibbrandt, Woolard \& Bhorat, 2001: 21; Leibbrandt, Poswell, Naidoo, Welch \& Woolard, 2005: 7).

Table 8 presents the Gini coefficients calculated using our asset index values.

12 The Gini coefficient can be explained in terms of the Lorenz curve. The Lorenz curve is a graphical depiction of income distribution whereby the cumulative percentage of the population arranged from the poorest to the richest is plotted on the horizontal axis. The cumulative percentage of income received by each cumulative percentage of population is plotted on the vertical axis. The Lorenz curve is then the graph of the cumulative percentage of income against the cumulative percentage of (ordered) population. 0 per cent of the population enjoys 0 per cent of the income and 100 per cent of the population enjoys 100 per cent of the income. The Lorenz curve therefore runs from one corner of the unit square to the diametrically opposite corner and if everyone had the same income the Lorenz curve would simply be the diagonal (See picture below).

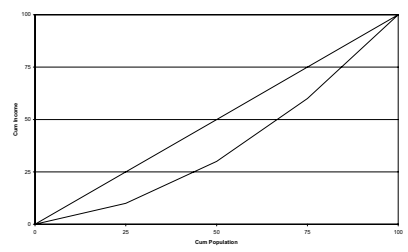

Any Lorenz curve (except for perfect equality) will therefore lie below the diagonal. The Gini coefficient is the ratio of the difference between the line of absolute equality (the diagonal) and the Lorenz curve to the triangular region below the diagonal (Fields, 2001:18; Sen, 1997:29,30). The estimated Gini coefficient ranges from 0 to 1, with 0 indicating absolute equality and 1 indicating absolute inequality. 
Table 8: Gini Coefficient based on the Asset Index, 1993, 1999 and 2004

\begin{tabular}{|l|c|c|c|}
\hline & Gini Coefficient & Standard Error & $\mathbf{9 5 \%}$ Confidence Intervals \\
\hline 1993 & 0.32 & 0.0114 & {$[0.2984514 ; 0.3441782]$} \\
\hline 1999 & 0.27 & 0.0041 & {$[0.2594645 ; 0.2760081]$} \\
\hline $\mathbf{2 0 0 4}$ & 0.24 & 0.0048 & {$[0.2282372 ; 0.2475510]$} \\
\hline
\end{tabular}

Source: PSLSD 1993 (SALDRU), OHS 1999 (Statistics SA), GHS 2004 (Statistics SA); Own Calculations

Two very important points can be observed from our results. Firstly, asset inequality was much lower than income inequality in the 1990s. In fact, estimated asset inequality was less than half estimated income inequality. Put differently, this suggests that the dispersion in assets and services was significantly less unequal than in the case of income or expenditure. Secondly, asset inequality as measured by the Gini coefficient declined in the first decade of democracy, in contrast to the reported increase in income inequality. Specifically, asset inequality as measured by the Gini coefficient, declined by 16 per cent from 0,32 in 1993 to 0,27 in 1999 and then by a further 11 per cent to 0,24 in 2004. The distribution of assets and services owned or received by South African households, therefore, became more equal between 1993 and 2004. The fact that the confidence intervals for the three years presented in Table 8 do not overlap indicates that the decrease in the Gini coefficient were statistically significant for both periods.

Table 9 presents estimated Gini coefficients for the four population groups in 1993, 1999 and 2004. The Gini coefficients for Asians and Whites were very low in all three years and the overlapping confidence intervals indicate that any changes were not statistically significant over the period. The Coloured Gini estimates were slightly higher, with a small increase between 1993 and 1999, but then declined to less than 0,1 in 2004. These changes, however, were also not statistically significant. 
Table 9: Comparisons of Inequality, using the Gini Coefficient

\begin{tabular}{|c|c|c|c|}
\hline & 1993 & 1999 & 2004 \\
\hline \multicolumn{4}{|l|}{ Race } \\
\hline \multirow[b]{2}{*}{ African } & 0.359 & 0.301 & 0.268 \\
\hline & {$\left[\begin{array}{ll}0.3422 & 0.3754\end{array}\right]$} & {$\left[\begin{array}{ll}0.2927 & 0.3102\end{array}\right]$} & {$\left[\begin{array}{ll}0.2591 & 0.2776\end{array}\right]$} \\
\hline \multirow[b]{2}{*}{ Coloured } & 0.105 & 0.121 & 0.098 \\
\hline & {$\left[\begin{array}{ll}0.0704 & 0.1397\end{array}\right]$} & {$\left[\begin{array}{ll}0.1067 & 0.1360\end{array}\right]$} & {$\left[\begin{array}{ll}0.0860 & 0.1108\end{array}\right]$} \\
\hline \multirow[b]{2}{*}{ Asian } & 0.025 & 0.041 & 0.029 \\
\hline & {$\left[\begin{array}{ll}0.0193 & 0.0309\end{array}\right]$} & {$\left[\begin{array}{ll}0.0239 & 0.0576\end{array}\right]$} & {$\left[\begin{array}{ll}0.0207 & 0.0367\end{array}\right]$} \\
\hline \multirow[b]{2}{*}{ White } & 0.024 & 0.027 & 0.020 \\
\hline & {$\left[\begin{array}{ll}0.0195 & 0.0276\end{array}\right]$} & {$\left[\begin{array}{ll}0.0232 & 0.0300\end{array}\right]$} & {$\left[\begin{array}{ll}0.0179 & 0.0218\end{array}\right]$} \\
\hline \multicolumn{4}{|l|}{ Location } \\
\hline \multirow[b]{2}{*}{ Rural } & 0.380 & 0.341 & 0.316 \\
\hline & {$\left[\begin{array}{ll}0.3552 & 0.4045\end{array}\right]$} & {$\left[\begin{array}{ll}0.3328 & 0.3501]\end{array}\right]$} & {$[0.3044 \quad 0.3279]$} \\
\hline \multirow[b]{2}{*}{ Urban } & 0.163 & 0.148 & 0.120 \\
\hline & {$[0.1361 \quad 0.1908]$} & {$[0.13850 .1571]$} & {$[0.1100 \quad 0.1308]$} \\
\hline \multicolumn{4}{|c|}{ Gender of Household Head } \\
\hline \multirow[b]{2}{*}{ Female } & 0.358 & 0.307 & 0.279 \\
\hline & {$\left[\begin{array}{ll}0.3409 & 0.3755\end{array}\right]$} & {$\left[\begin{array}{ll}0.2985 & 0.3147\end{array}\right]$} & {$\left[\begin{array}{ll}0.2677 & 0.2912\end{array}\right]$} \\
\hline \multirow[b]{2}{*}{ Male } & 0.303 & 0.240 & 0.209 \\
\hline & {$\left[\begin{array}{ll}0.2770 & 0.3281\end{array}\right]$} & {$\left[\begin{array}{ll}0.2322 & 0.2472\end{array}\right]$} & {$\left[\begin{array}{ll}0.2007 & 0.2181\end{array}\right]$} \\
\hline
\end{tabular}

Source: $\quad$ PSLSD 1993 (SALDRU), OHS 1999 (Statistics SA), GHS 2004 (Statistics SA); Own Calculations

Notes: $\quad 95$ per cent Confidence intervals are in parentheses and are corrected according to frequency weights, and the primary sampling unit.

It is clear, though, from the Gini coefficients above that aggregate asset inequality in South Africa has been driven by asset inequality amongst African households. Although it declined by about 25 per cent between 1993 and 1999, the Gini coefficients for Africans remained well above the national Gini estimates for all three years under consideration. In the case of African households the changes in the Gini coefficient were statistically significant as indicated by the confidence intervals not overlapping over the three years.

Rural inequality remained significantly higher than urban inequality in all three years. In fact, the Gini estimates suggested that rural inequality remained more than double the level of urban inequality. Rural inequality declined from 0.38 in 1993 to 0,316 in 2004, with most of the decrease taking place between 1993 and 1999. In contrast, urban inequality declined more between 1999 and 2004, from 0,148 to 0,120, after the initial decrease from 0,163 in 1993.

While inequality decreased both for male and female headed households, inequality as measured by the Gini was higher for female headed households in all three years. The Gini coefficient for female headed households decreased from 0,359 in 1993 to 0,279 in 2004. Male headed households experienced a larger decline in estimated inequality with the Gini declining from 0,303 in 1993 to 0,209 in 2004. In addition, the gap between the Gini estimates for female as opposed to male headed households widened over the period. All these changes in the Gini coefficient were statistically significant. 


\section{Lorenz Curves for the Distribution of the Asset Indices}

Lorenz curves were also derived for the distribution of our asset indices across the three years. Asset index values were ranked from lowest to highest and the cumulative distribution of the population was plotted on the horizontal axis and the cumulative distribution of asset values on the vertical axis.

Figure 12 shows the national Lorenz curves for 1993, 1999 and 2004. Decreasing inequality between 1993 and 1999 and between 1999 and 2004 are illustrated by the fact that the 1999 Lorenz curve lies above the 1993 curve and that the 2004 curve lies above the 1999 curve. In 1993 the bottom 40 per cent of households owned or had access to approximately 15 per cent of the total assets and services in the economy. By 2004, this had increased to more than 20 per cent.

Figure 12: Lorenz Curves, 1993, 1999 and 2004

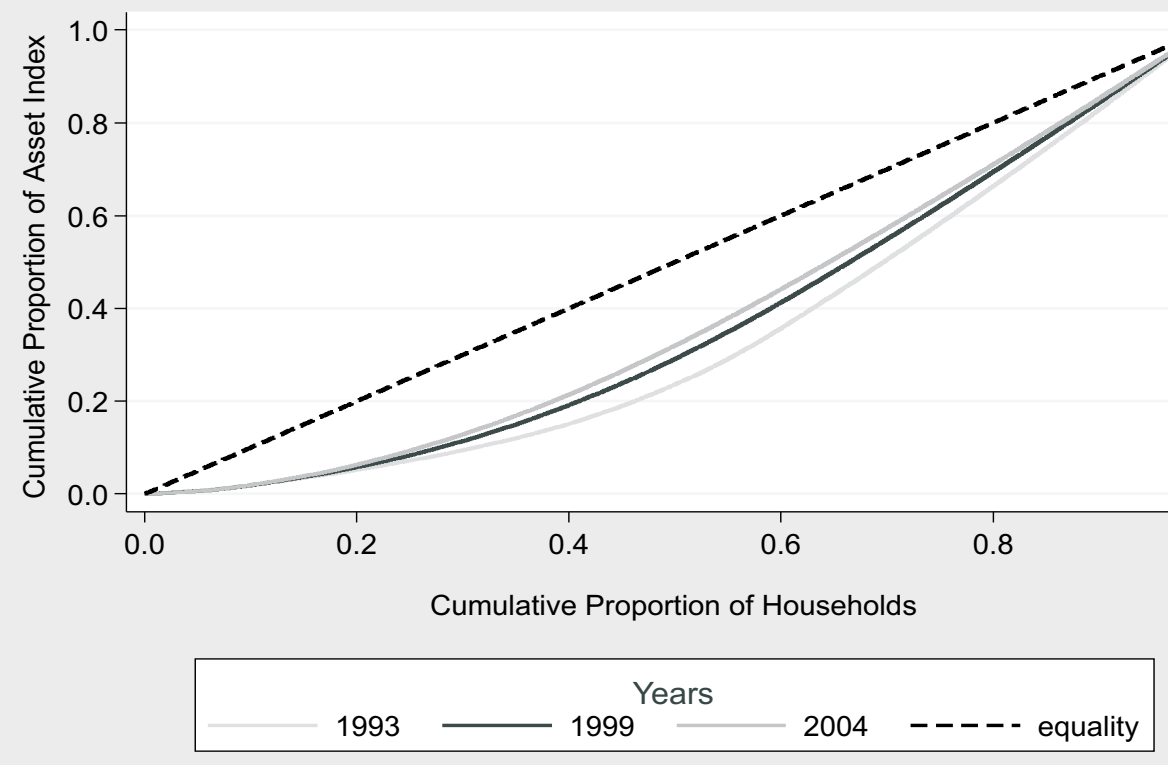

Source: PSLSD 1993 (SALDRU), OHS 1999 (Statistics SA), GHS 2004 (Statistics SA); Own Calculations 
Figure 13 illustrates the relative higher inequality amongst African households in 2004 well. The Lorenz curves for both Whites and Asians lie very close to the "equality" curve, indicating relatively low levels of inequality. The position of the Lorenz curves for Coloured and especially for African households is indicative of relatively higher levels of inequality. For example, the Lorenz curve for White households indicates that a cumulative 60 per cent of those households had access to or owned almost 60 per cent of the total pool of assets and services in the hands of White households in 2004. The Lorenz curve for African households indicates that a cumulative 60 per cent of African households only owned or had access to about 40 per cent of the total pool of assets and services in the hands of African households in the same year.

Figure 13: Lorenz Curves by Race 2004

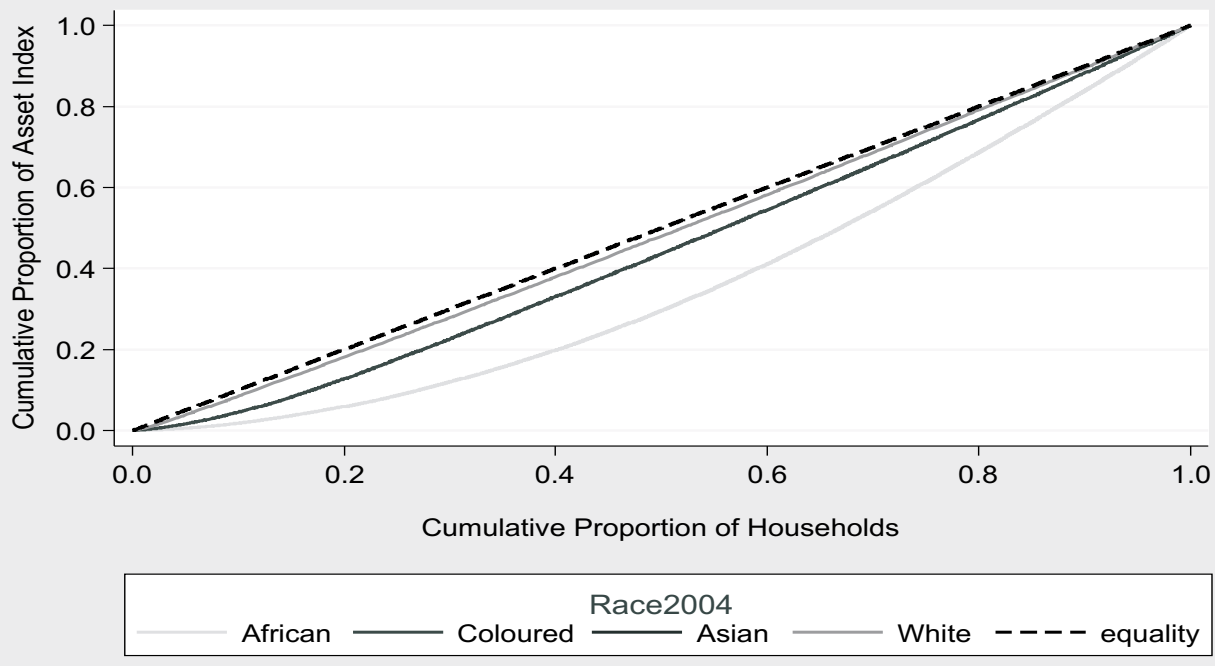

Source: PSLSD 1993 (SALDRU), OHS 1999 (Statistics SA), GHS 2004 (Statistics SA); Own Calculations

Figure 14 presents the Lorenz curves for African households for 1993, 1999 and 2004. 
Figure 14: Lorenz Curves for Africans, 1993, 1999, 2004

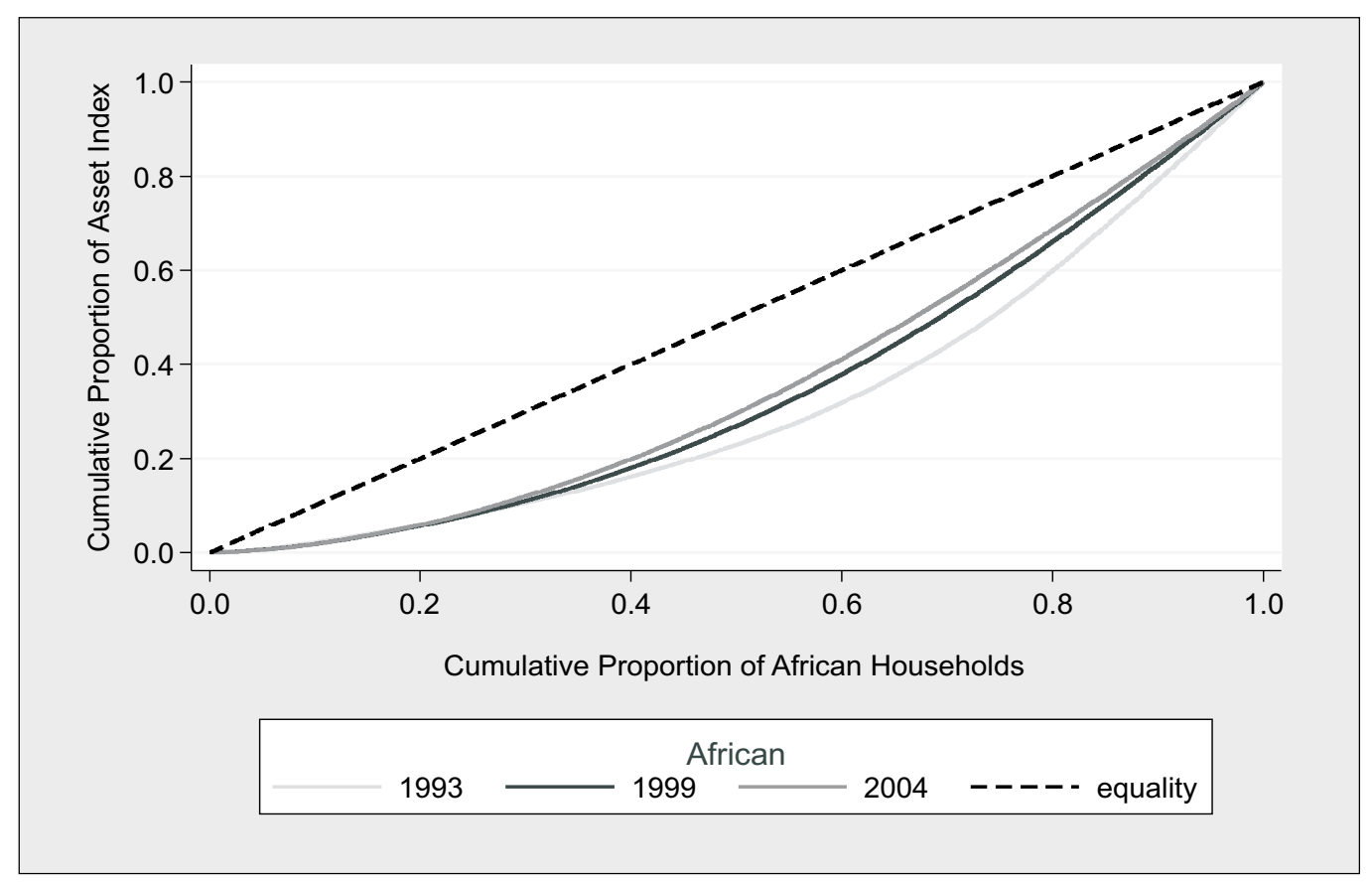

Source: PSLSD 1993 (SALDRU), OHS 1999 (Statistics SA), GHS 2004 (Statistics SA); Own Calculations

The curves illustrate how inequality has decreased between 1993 and 1999 and further between 1999 and 2004, with the 1999 curve lying above the 1993 curve and the 2004 curve above both curves. For example, 60 per cent of African households had access to or owned about 30 per cent of the total assets and services in the hands of African households in 1993. In 2004, inequality has been reduced to the extent that 60 per cent of the households owned or had access to about 40 per cent of the pool of assets and services in the hands of African households. The non-linearity in the reduction of asset and service inequality is partially evident in the above, as the size of the change in inequality was clearly greater in the 1993 to 1999 period, relative to the 1999-2004 period. 


\section{The Decomposition of Non-income Inequality}

When the population can be divided into mutually exclusive, exhaustive subgroups there is a degree of inequality within the subgroups as well as between them. In the South African context, the strong inequality between racial groups has always been a significant driver of aggregate inequality (See Leibbrandt, Woolard \& Bhorat, 2001: 24). The Theil index is a well-known measure of inequality that allows us to decompose overall inequality into the contribution from within group inequality and the contribution due to between-group inequality. ${ }^{13}$

Table 10 presents Theil decompositions for a range of subgroups. Looking at the decompositions by race, it is clear that inequality within population groups had become more important in determining aggregate inequality. Between 1993 and 2004, the contribution of within-race inequality to total inequality increased by about 20 percentage points to almost 82 per cent. The bulk of the increase (about 14 per cent) took place between 1993 and 1999. The notion of within-race group asset inequality driving overall inequality is consistent with the income based evidence. However, the share of intra-African inequality in driving overall inequality is extraordinarily high. It could possibly speak, once again to the extent to which South Africa's fruits of economic growth have been maldistributed. In this case, it refers to African households at the top end of the distribution benefiting from economic growth rather than African households at the bottom.

$$
T=T_{B}+\sum q_{i} T_{i}
$$

Where $T_{i}$ is the Thiel-T inequality measure within the ith group; $q_{i}$ is the proportion of income accruing to the ith group; and $T_{B}$ is the between-group contribution. $T_{B}$ is calculated the same way as $T$, but assumes that al incomes within a group are equal. 
Table 10: Contribution of Within-group and Between-group Inequality to Total Asset Inequality, using the Theil-index

\begin{tabular}{|l|r|r|r|}
\hline & $\mathbf{1 9 9 3}$ & $\mathbf{1 9 9 9}$ & $\mathbf{2 0 0 4}$ \\
\hline By Race & & & $81.9 \%$ \\
\hline Within-group inequality & $63.4 \%$ & $77.0 \%$ & $18.1 \%$ \\
\hline Between-group inequality & $36.6 \%$ & $23.0 \%$ & $100.0 \%$ \\
\hline Total Inequality & $100.0 \%$ & $100.0 \%$ & $65.7 \%$ \\
\hline By Location & & & $34.3 \%$ \\
\hline Within-group inequality & $60.4 \%$ & $63.7 \%$ & $100.0 \%$ \\
\hline Between-group inequality & $39.6 \%$ & $36.3 \%$ & \\
\hline Total Inequality & $100.0 \%$ & $100.0 \%$ & $97.1 \%$ \\
\hline By Gender of Household Head & & & $2.9 \%$ \\
\hline Within-group inequality & $97.9 \%$ & $97.1 \%$ & $100.0 \%$ \\
\hline Between-group inequality & $2.1 \%$ & $2.9 \%$ & \\
\hline Total Inequality & $100.0 \%$ & $100.0 \%$ & \\
\hline
\end{tabular}

Source: PSLSD 1993 (SALDRU), OHS 1999 (Statistics SA), GHS 2004 (Statistics SA); Own Calculations

Note: $\quad$ Actual Theil-index values are in Appendix $L$

Aggregate inequality decomposed according to location, in this case urban vs. rural, shows that the contribution of within-group inequality increased slightly by about five percentage points between 1993 and 2004. In 2004 within-group inequality contributed almost 66 per cent to total inequality as decomposed by location.

When asset inequality is decomposed according to the gender of the household head, inequality was almost exclusively driven by within-group inequality, with an almost stable share contribution of around 97 per cent in all three years. This means that genderbased asset inequality had very little to do with inequality between female and male headed households and was mostly driven by inequality within female and male headed households.

The results above showed that the distribution of assets and services among South African households became less unequal between 1993 and 2004, the bulk of the decrease in inequality taking place between 1993 and 1999. Again, inequality remained relatively higher for the particularly vulnerable groups, namely African households, rural households and female-headed households. Finally, inequality within subgroups (i.e. race, location and gender of household head) has become more important in determining aggregated inequality than inequality between subgroups. The share of intra-African inequality in driving overall inequality has become extraordinarily high and may be a reflection of African households at the upper end of the distribution benefiting relatively more from economic growth in the post apartheid period than their counterparts at the bottom. 


\section{Conclusion}

The aim of this report was to provide an analysis of the shifts in non-income welfare that have occurred over the period 1993 to 2004. The analysis serves as a complement to existing research which has focused on shifts in income poverty and inequality in the post-apartheid period. In addition, the study is one of only a few that provides a complete overview of the first decade of democracy by means of the comprehensive time period it covers. We used a technique called factor analysis to construct an asset index as an alternative, non-income based, measure of welfare. Variables reflecting household access to a range of services and assets were used in the construction of our asset index.

A descriptive overview of the shifts in access to services and assets provided strong evidence that government asset and service delivery between 1993 and 2004 was pro-poor in nature. The increases in delivery across all assets and services were propoor in both relative and absolute terms. This means that households in the bottom expenditure deciles benefited relatively more from government service delivery. Despite the relative pro-poor nature of service delivery, significant backlogs in particularly the bottom expenditure deciles still exist. Large proportions of poor households still don't have access to basic services, with the backlogs in access to flush/chemical toilets and piped water particularly prominent.

When standard FGT measures of poverty were applied to our asset index values, statistically significant decreases in the headcount asset poverty rates across all covariates were found. In addition, the poverty gap rates declined across all covariates. CDF graphs confirmed that poverty decreased for all covariates irrespective of the choice of poverty line. African, rural and female headed households, however, remained particularly vulnerable with the bottom households witnessing relatively slower increases in their access to services and assets between 1993 and 2004. This trend is even more evident when African female-headed households in rural areas were examined. This raises a very important policy issue, namely an appropriate policy response designed to deal with the core of the marginalised in terms of entitlement deprivation.

A series of inequality measures were applied to our asset index. The Gini coefficients showed that across all covariates, asset inequality decreased between 1993 and 2004. In addition, the estimated asset inequality was much lower than income inequality, suggesting a more equal distribution of assets and services. The Theil decompositions indicated that within-group inequality has increased in importance in determining aggregate inequality. The share of intra-African inequality in driving overall inequality is particularly high and may be a reflection of African households at the upper end of the distribution benefiting relatively more from economic growth. 
The descriptive overview of the increased delivery of government services provided the initial evidence of non-linearity in service delivery between 1993 and 2004, with household access to services and assets growing relatively faster between 1993 and 1999 than between 1999 and 2004. The asset poverty and inequality measures confirmed this trend, with both asset poverty and asset inequality decreasing at a faster rate between 1993 and 1999 than between 1999 and 2004. This is a puzzling result given government's increased expenditure allocation to service delivery after 2000. This may be evidence of the ongoing inability of certain government departments or spheres of government to spend allocated funds or the difficulty in reaching the core of households at the bottomend of the distribution.

Ultimately then, the above study, through the construction of a non-income based measure of welfare has attempted an analysis of the shifts in non-income poverty and inequality in the first decade of democracy. While it has been shown that non-income poverty are significantly decreased over the period, in order to be able to fully evaluate the welfare changes in the post-apartheid period, a welfare measure has to be constructed that will include both non-income and income variables. 


\section{References}

Bhorat, H., Poswell, L. \& Naidoo, P. 2004. Dimensions of Poverty in Post-Apartheid South Africa 1996-2001. A Poverty Status Report. Cape Town:

Development Policy Research Unit, University of Cape Town. July 2004.

Bhorat, H. \& Shaikh, N. 2004. Poverty and Labour Markers of HIV+ Households: An Exploratory Methodological Analysis. Development Policy Research Unit Working Paper No 04/83. February 2004. Cape Town: University of Cape Town.

Bentley, K. 2004. Women's Human Rights and the Feminisation of Poverty in South Africa. In Review of African Political Economy. No. 100. pp.247-261.

Booysen, F le R. 2002. "Using Demographic and Health Surveys to Measure Poverty - an Application to South Africa". In Journal for Studies in Economics and Econometrics. Vol 26. No 3. pp.53-70.

Booysen, F le R. et. al. 2004. "Poverty and Inequality Analysis for Seven African Countries, using Asset Indices Constructed from DHS data". Interim report for PEP-PMMA Meeting. 16-20 June 2004. Dakar, Senegal.

Child, D. 1969. The Essentials of Factor Analysis. London: Holt, Rinehart and Winston

Catell, R. B. 1965. Factor Analysis: An Introduction to Essentials. I. The Purpose and Underlying Models. Biometrics. Vol 21(1). March: 190-215

Department of Minerals and Energy. 2003. Frequently asked questions regarding the proposed policy of providing free basic electricity (FBE). 23 April 2003. Available online at www.dme.gov.sa/energy/faq_energy.htm

Fields, G.S. 2001. Distribution and Development: A New Look at the Developing World. New York: Russel Sage Foundation.

Filmer, D. \& Pritchett, L.H. 2001. "Estimating Wealth Effects without Expenditure Data or Tears: An Application to Educational Enrollments in States in India". In Demography. Vol 38, No 1. February 2001. pp.115-132. 
Foster, J.E., Greer, J. \& Thorbecke, E. 1984. A Class of Decomposable Poverty Measures. Econometrics. Vol 52.

Hoogeveen , J. \& Özler, B. 2006. Not Separate, Not Equal: Poverty and Inequality in Post-Apartheid South Africa. In Bhorat, H. \& Kanbur, R. 2006. Poverty and Policy in Post-Apartheid South Africa. Pretoria: HSRC Press

Leibbrandt, M., Woolard, I \& Bhorat, H. 2001. Understanding Contemporary Household Inequality in South Africa. In Bhorat, H. et. al. (eds.) Fighting Poverty: Labour Markets and Inequality in South Africa. Landsdowne: UCT Press.

Leibbrandt, M., Levinsohn, J. \& McCrary, J. 2005. Incomes in South Africa since the fall of Apartheid. NBER Working Paper. No. 11384. National Bureau for Economic Research: Cambridge.

Leibbrandt, M., Poswell, L., Naidoo, P., Welch, M. \& Woolard, I. 2005. Measuring Recent Changes in South African Inequality and Poverty using 1996 and 2001 Census Data. Development Policy Research Unit Working Paper No 05/94. June 2005. Cape Town; University of Cape Town

McKenzie, D.J. 2003. "Measuring Inequality with Asset Indicators". BREAD Working Paper No 042. August 2003.

National Treasury. 2003. Intergovernmental Fiscal Review 2003. April 2003. Pretoria: Government Printer.

National Treasury. 2005. Estimates of National Expenditure 2005. February 2005. Pretoria: Government Printer.

Ravallion, M. 1994. Poverty Comparisons. Chur: Harwood Academic Publishers.

Ravallion, M. 2004. Pro-poor Growth: A Primer. World Bank Policy Research Working Paper 3242. March 2004.

Ravallion, M. \& Chen, S. 2003. Measuring Pro-poor Growth. Economic Letters. 78 (1). pp 93-99. 
Southern Africa Labour and Development Research Unit (SALDRU). 1993. Project for Statistics on Living Standards and Development (PSLSD). The South African Integrated Household Survey. Cape Town. Overview and background information available from http://www.cssr.uct.ac.za/ saldru_pslsd.html

Southern Africa Labour and Development Research Unit (SALDRU). 1993. Project for Statistics on Living Standards and Development (PSLSD). The South African Integrated Household Survey. Cape Town. Dataset.

Sahn, D.E. \& Stifel, D.C. 2000. "Poverty Comparisons over Time and Across Countries in Africa." In World Development. Vol. 28 No 12, pp. 2123-2155.

Sen, A. 1997. On Economic Inequality. Clarendon Press: Oxford

Statistics South Africa. 1995. October Household Survey. Pretoria: Own publication. (Dataset)

Statistics South Africa. 2000. October Household Survey 1999. Statistical Release P0317. Pretoria: Own publication

Statistics South Africa. 2003. General Household Survey July 2002. Statistical Release P0318. Pretoria: Own Publication.

Statistics South Africa. 2005. General Household Survey July 2004. Statistical Release P0318. Pretoria: Own Publication.

National Treasury. 2005. National Estimates of Expenditure. February 2005. Pretoria: Government Printer.

Van der Berg, S. 2006. Public Spending and the Poor Since the Transition to Democracy. In H. Bhorat and R. Kanbur. 2006. Poverty and Policy in Post-Apartheid South Africa. HSRC Press: Pretoria. 
World Bank. 2000. Round I Country Reports on Health, Nutrition, Population Conditions among Poor and Better-off Countries. Available from http://web.worldbank.org/ WBSITE/EXTERNAL/TOPICS/EXTHEALTHNUTRITIONANDPOPULATION/ EXTPAH/0,,menuPK:400482 pagePK:149018 piPK:149093 the SitePK:400476,00.html

World Bank. 2004. Round II Country Reports on Health, Nutrition, Population Conditions among Poor and Better-off Countries. Available from http://web.worldbank.org/ WBSITE/EXTERNAL/TOPICS/EXTHEALTHNUTRITIONANDPOPULATION/ EXTPAH/0,,menuPK:400482 pagePK:149018 piPK:149093 the SitePK:400476,00.html

World Bank. 2005. Poverty Manual: Introduction to Poverty Analysis. World Bank Institute. August 2005. Available from http://siteresources.worldbank.org/PGLP/ Resources/PovertyManual.pdf 


\section{Appendix A}

Growth Incidence Curve: Use of Electricity for Cooking, 1993 - 2004

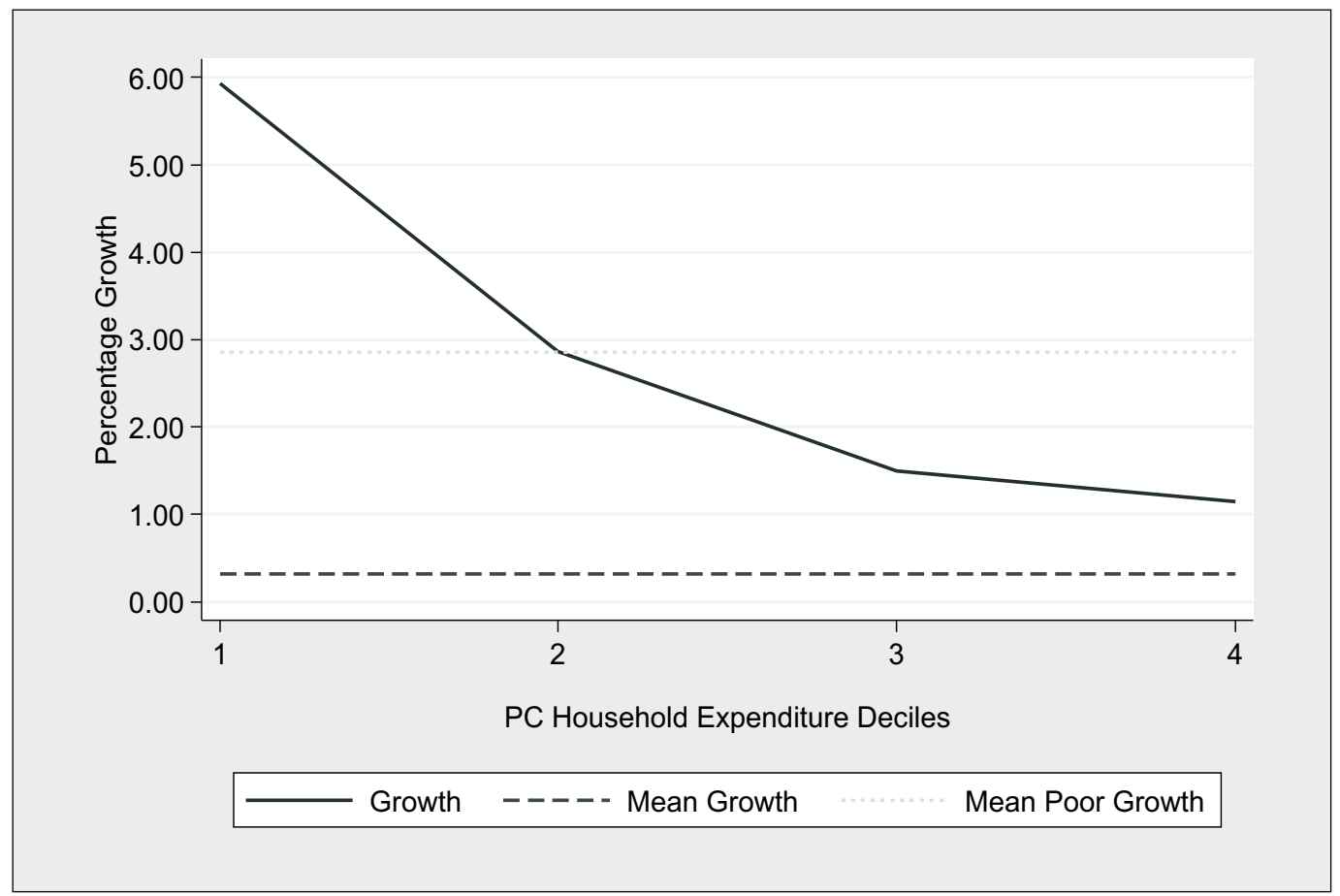

Source: PSLSD 1993 (SALDRU), GHS 2004 (Statistics SA); Own Calculations 


\section{Appendix B}

Household Ownership of Selected Assets, 1993 - 1999 - 2004

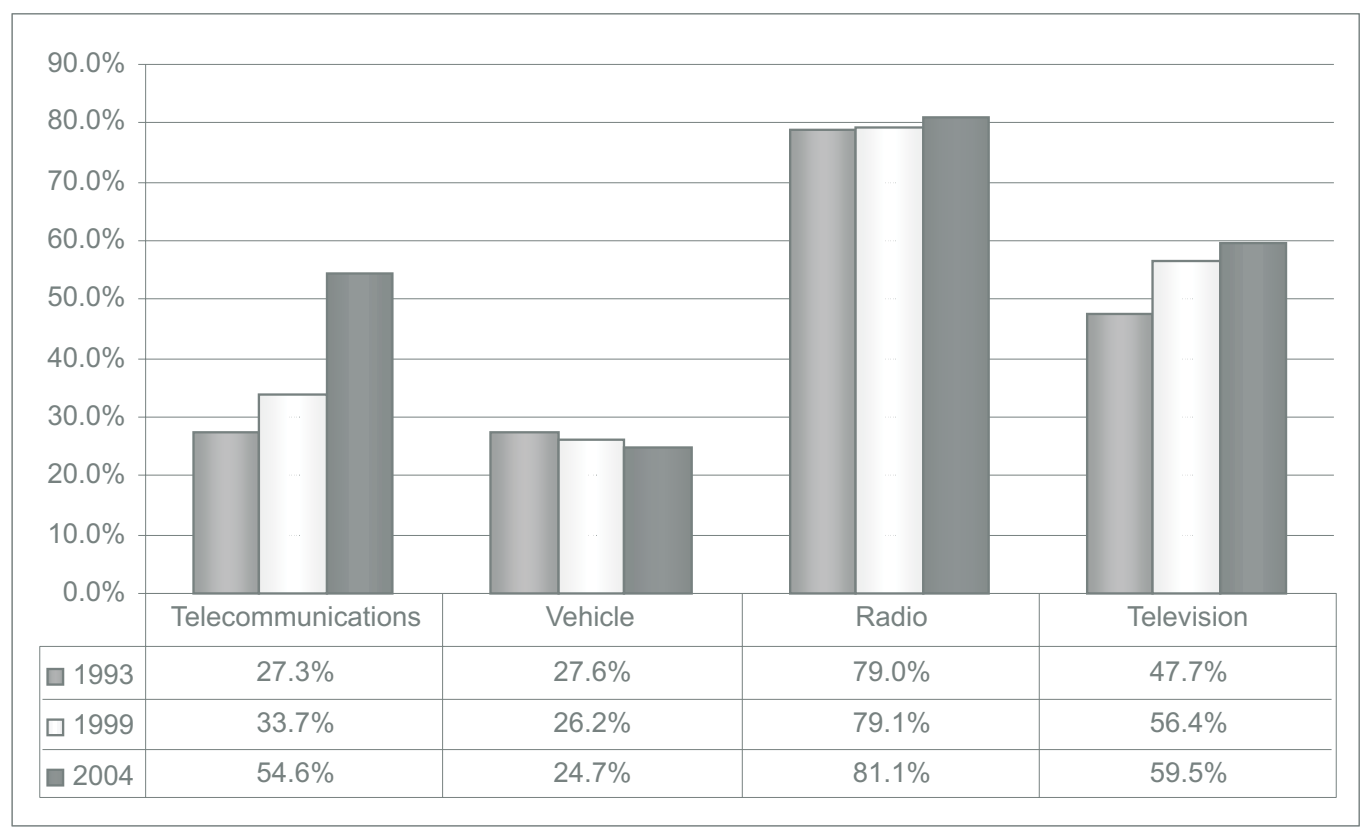

Source: PSLSD 1993 (SALDRU), OHS 1999 (Statistics SA), GHS 2004 (Statistics SA); Own Calculations 


\section{Appendix C}

\section{Why Pool the Data?}

Factor analysis was performed on the pooled data set and a set of weights were derived for the pooled sample. This was done in order to allow us to compare the asset ownership over the three surveys. The weights on the asset variables which explain most of the variation among households in 1993 may differ from the weights on the asset variables which explain most of the variation in the other two years. For example, if relatively few households owned an asset (say a phone) in 1993, but almost all households owned that asset in 2004, factor analysis for 1993 only will put relatively more weight on owning a phone than would the factor analysis done for 2004. Weights derived from a pooled dataset explain variation over time as well as across households (See McKenzie, 2003: 7; Sahn \& Stifel, 2000: 2125, 2126, 2153).

As an experiment, factor analysis was also performed separately on the three datasets and three separate sets of weights for 1993, 1999 and 2004 were derived. The results of the pooled analysis were compared to the results from the three separate datasets. Across all four datasets (one pooled and three individual), the signs of the estimated asset weights remained unchanged. This means that the same set of assets across the four datasets contributed positively to asset wealth. When looking at the actual numerical values of the asset weights, there were small differences across all the datasets. Across all datasets, however, the same four assets had relatively larger positive weights, namely access to piped water, use of electricity for cooking, use of electricity for lighting and access to flush/chemical toilets, with only minor differences in the actual numerical values of the weights).

In the main analysis, two asset poverty lines were estimated, using the asset index values at the $20^{\text {th }}$ percentile and the $40^{\text {th }}$ percentile of the asset index distribution in 1993 . These two poverty lines were applied to the asset index distribution in 1999 and 2004 separately to derive headcount poverty rates for the two years. Again, as an experiment, a number of different scenarios were examined, with the results in Table C 1.

Two asset poverty lines were estimated, using the results from the factor analysis performed on the 1993 data only. Again these two lines were simply the asset index values at the $20^{\text {th }}$ percentile and at the $40^{\text {th }}$ percentile of the asset index distribution. These two poverty lines were then applied to the 1999 asset index distribution and the 2004 asset index distribution. What is different from our main analysis is that factor analysis was performed on the individual datasets and different weights were derived for 1999 and 
2004. The assets therefore carry different weights across the three datasets. When the 1993 poverty lines were applied to 1999 and 2004 datasets respectively there were no significant changes in the headcount poverty rates at the $20^{\text {th }}$ percentile (see "unpooled data" column for these rates). At the $40^{\text {th }}$ percentile poverty line, the headcount poverty rates did decrease, but not with the same magnitudes than when the pooled dataset was used.

Table C 1: Headcount Poverty Rates using differently derived Poverty Lines

\begin{tabular}{|l|r|r|r|r|r|r|}
\hline & \multicolumn{3}{|c|}{ 40th percentile } & \multicolumn{3}{c|}{ 20th percentile } \\
\hline & Pooled data & $\begin{array}{c}\text { Un-pooled } \\
\text { data }\end{array}$ & $\begin{array}{c}\text { "Basket of } \\
\text { assets" }\end{array}$ & Pooled data & $\begin{array}{c}\text { Un-pooled } \\
\text { data }\end{array}$ & $\begin{array}{c}\text { "Basket of } \\
\text { assets" }\end{array}$ \\
\hline $\mathbf{1 9 9 3}$ & $40.0 \%$ & $40.0 \%$ & $40.0 \%$ & $20.3 \%$ & $19.9 \%$ & $19.9 \%$ \\
\hline $\mathbf{1 9 9 9}$ & $28.5 \%$ & $31.5 \%$ & $28.6 \%$ & $12.0 \%$ & $19.8 \%$ & $12.7 \%$ \\
\hline $\mathbf{2 0 0 4}$ & $21.6 \%$ & $27.7 \%$ & $23.5 \%$ & $9.7 \%$ & $17.9 \%$ & $11.5 \%$ \\
\hline
\end{tabular}

Source: PSLSD 1993 (SALDRU), OHS 1999 (Statistics SA), GHS 2004 (Statistics SA); Own Calculations

This method raises some questions. The asset index values at the $20^{\text {th }}$ and $40^{\text {th }}$ percentiles of the 1993 asset index distribution are reflective of the weights which were the result of the factor analysis performed on the 1993 dataset. If these asset values are used to calculate headcount rates for the 1999 and 2004 datasets, they are applied to asset index distributions which were the results from two additional factor analysis processes which produce two additional and different sets of asset weights. This means that the two poverty lines are in essence meaningless in the 1999 and 2004 asset index distributions.

In attempt to find more meaningful poverty lines, the "basket" of assets that constituted the $20^{\text {th }}$ percentile and $40^{\text {th }}$ percentile poverty lines in 1993 (using the asset index distribution which was the result of factor analysis applied only to the 1993 dataset) were investigated. It was found that the asset index value that lies at the $20^{\text {th }}$ percentile in 1993 was comprised of a very specific combination of assets. In other words, the households with that particular asset index value all had access to the same set of services/household assets. ${ }^{14}$ When the asset index value at the $40^{\text {th }}$ percentile was investigated, a similar result was found. ${ }^{15}$

14 In the case of the $20^{\text {th }}$ percentile, these were formal dwelling, low quality wall, corrugated roof, borehole as water source, candle as source for lighting, wood as energy source for cooking, pit toilet, and no ownership of telecommunications, vehicle or television.

15 The households with that specific asset index value has access to a formal dwelling with a corrugated roof, high quality wall, piped water, candle as source of light, wood as energy source for cooking and a pit toilet, and ownership of a television but no other asset 
Using the two "baskets of assets", two poverty lines for 1999 and two poverty lines for 2004 were derived. For example, the weights derived from 1999 factor analysis were applied to the combination of assets which formed the "basket" at the $20^{\text {th }}$ percentile in 1993 . The result was an asset index value for 1999 (with 1999 asset weights) which reflected the same set of assets as the $20^{\text {th }}$ percentile of the 1993 distribution. When this asset index value was used at the poverty line in 1999, it was found that the share of households with those assets or less had declined to 12,7 per cent. In other words, the headcount asset poverty rate as measured by that set of assets declined. The table above shows the result of the similar process for the $20^{\text {th }}$ percentile poverty line in 2004 and the $40^{\text {th }}$ percentile line in 1999 and 2004. Across the board, headcount poverty rates declined significantly and in addition followed the pattern of the pooled data very closely. 


\section{Appendix D}

\section{Evaluating the Reliability of the Asset Index}

\section{Internal Coherence}

The internal coherence of the asset index can be evaluated by comparing the mean of each of the variables included in the asset index across poor, middle-income and rich households. In this analysis, the total number of households in each year was divided into quartiles based on their asset index values. In other words, the total number of households in every year was categorised into the poorest 25 per cent, the second poorest 25 per cent, the next 25 per cent and the richest 25 per cent, based on the asset index. ${ }^{16}$

Table D 1 shows the mean (average) asset ownership for each asset according to the asset index quartile for all three years. The asset index performs well on this test as there are significant differences in asset ownership across the household quartiles for all three years. households in the poorest 40 per cent, the middle 40 per cent and the richest 20 per cent) does not follow the usual definitions of poverty. It is just a tool we use to assist us in evaluating the asset index we have constructed. This classification for the 2004 data did not divide the number of households in exactly equal quartiles due to the fact that clumping of households occurred at the top end of the distribution. 
Table D 1: Means of Asset Index Variables

\begin{tabular}{|c|c|c|c|c|c|}
\hline & & \multicolumn{4}{|l|}{ Means } \\
\hline & & Bottom 25\% & 2nd $25 \%$ & 3rd 25\% & Top 25\% \\
\hline \multirow[t]{3}{*}{ Formal Dwelling } & 1993 & 0.18 & 0.64 & 0.92 & 1.00 \\
\hline & 1999 & 0.37 & 0.73 & 0.88 & 1.00 \\
\hline & 2004 & 0.34 & 0.74 & 0.88 & 1.00 \\
\hline \multirow[t]{3}{*}{ Traditional Dwelling } & 1993 & 0.36 & 0.03 & 0.00 & 0.00 \\
\hline & 1999 & 0.40 & 0.03 & 0.00 & 0.00 \\
\hline & 2004 & 0.46 & 0.05 & 0.00 & 0.00 \\
\hline \multirow[t]{3}{*}{ Thatch Roof } & 1993 & 0.23 & 0.02 & 0.01 & 0.00 \\
\hline & 1999 & 0.24 & 0.01 & 0.01 & 0.00 \\
\hline & 2004 & 0.25 & 0.00 & 0.01 & 0.00 \\
\hline \multirow[t]{3}{*}{ Tile Roof } & 1993 & 0.00 & 0.01 & 0.07 & 0.60 \\
\hline & 1999 & 0.00 & 0.02 & 0.13 & 0.59 \\
\hline & 2004 & 0.00 & 0.03 & 0.10 & 0.69 \\
\hline \multirow[t]{3}{*}{ Corrugated Roof } & 1993 & 0.73 & 0.80 & 0.46 & 0.17 \\
\hline & 1999 & 0.70 & 0.84 & 0.58 & 0.17 \\
\hline & 2004 & 0.70 & 0.87 & 0.50 & 0.18 \\
\hline \multirow[t]{3}{*}{ Low Quality Wall } & 1993 & 0.85 & 0.35 & 0.12 & 0.00 \\
\hline & 1999 & 0.69 & 0.31 & 0.09 & 0.00 \\
\hline & 2004 & 0.64 & 0.24 & 0.06 & 0.00 \\
\hline \multirow[t]{3}{*}{ Piped Water } & 1993 & 0.01 & 0.43 & 0.94 & 1.00 \\
\hline & 1999 & 0.08 & 0.59 & 0.97 & 1.00 \\
\hline & 2004 & 0.12 & 0.62 & 0.99 & 1.00 \\
\hline \multirow[t]{3}{*}{ Public Tap } & 1993 & 0.41 & 0.27 & 0.01 & 0.00 \\
\hline & 1999 & 0.42 & 0.26 & 0.01 & 0.00 \\
\hline & 2004 & 0.46 & 0.24 & 0.00 & 0.00 \\
\hline \multirow[t]{3}{*}{ Surface Water } & 1993 & 0.31 & 0.05 & 0.00 & 0.00 \\
\hline & 1999 & 0.33 & 0.04 & 0.00 & 0.00 \\
\hline & 2004 & 0.28 & 0.03 & 0.00 & 0.00 \\
\hline \multirow[t]{3}{*}{ Electricity for Light } & 1993 & 0.01 & 0.16 & 0.92 & 1.00 \\
\hline & 1999 & 0.09 & 0.70 & 1.00 & 1.00 \\
\hline & 2004 & 0.31 & 0.91 & 1.00 & 1.00 \\
\hline \multirow[t]{3}{*}{ Paraffin for Light } & 1993 & 0.32 & 0.37 & 0.03 & 0.00 \\
\hline & 1999 & 0.29 & 0.10 & 0.00 & 0.00 \\
\hline & 2004 & 0.15 & 0.02 & 0.00 & 0.00 \\
\hline \multirow[t]{3}{*}{ Candle for Light } & 1993 & 0.65 & 0.46 & 0.04 & 0.00 \\
\hline & 1999 & 0.61 & 0.18 & 0.00 & 0.00 \\
\hline & 2004 & 0.54 & 0.06 & 0.00 & 0.00 \\
\hline \multirow[t]{3}{*}{ Electricity for Cooking } & 1993 & 0.00 & 0.02 & 0.79 & 1.00 \\
\hline & 1999 & 0.00 & 0.22 & 0.90 & 1.00 \\
\hline & 2004 & 0.01 & 0.41 & 0.96 & 1.00 \\
\hline Paraffin for Cooking & 1993 & 0.25 & 0.50 & 0.09 & 0.00 \\
\hline & 1999 & 0.38 & 0.42 & 0.04 & 0.00 \\
\hline & 2004 & 0.32 & 0.27 & 0.01 & 0.00 \\
\hline Wood for Cooking & 1993 & 0.69 & 0.29 & 0.01 & 0.00 \\
\hline & 1999 & 0.56 & 0.21 & 0.01 & 0.00 \\
\hline & 2004 & 0.61 & 0.18 & 0.00 & 0.00 \\
\hline Flush/Chemical T oilet & 1993 & 0.00 & 0.22 & 0.89 & 1.00 \\
\hline & 1999 & 0.01 & 0.32 & 0.90 & 1.00 \\
\hline & 2004 & 0.03 & 0.32 & 0.95 & 1.00 \\
\hline Pit Toilet & 1993 & 0.58 & 0.52 & 0.06 & 0.00 \\
\hline & 1999 & 0.53 & 0.46 & 0.05 & 0.00 \\
\hline & 2004 & 0.51 & 0.44 & 0.02 & 0.00 \\
\hline No Toilet & 1993 & 0.36 & 0.10 & 0.00 & 0.00 \\
\hline & 1999 & 0.32 & 0.05 & 0.00 & 0.00 \\
\hline & 2004 & 0.32 & 0.04 & 0.00 & 0.00 \\
\hline Telecommunications & 1993 & 0.00 & 0.02 & 0.18 & 0.90 \\
\hline & 1999 & 0.03 & 0.11 & 0.28 & 0.95 \\
\hline & 2004 & 0.23 & 0.44 & 0.57 & 0.98 \\
\hline Vehicle & 1993 & 0.03 & 0.09 & 0.19 & 0.80 \\
\hline & 1999 & 0.04 & 0.10 & 0.16 & 0.76 \\
\hline & 2004 & 0.02 & 0.08 & 0.09 & 0.87 \\
\hline Television & 1993 & 0.07 & 0.30 & 0.56 & 0.99 \\
\hline & 1999 & 0.19 & 0.43 & 0.66 & 0.99 \\
\hline & 2004 & 0.16 & 0.54 & 0.71 & 0.99 \\
\hline
\end{tabular}

Source: PSLSD 1993 (SALDRU), OHS 1999 (Statistics SA), GHS 2004 (Statistics SA); Own Calculations 
In 1993, only 18 per cent of the bottom 25 per cent of households (as calculated according to the asset index distribution) had access to a formal dwelling. Looking at the next 25 per cent of households, around 65 per cent of households had access to a formal dwelling. Of the households in the third quartile, 92 per cent had access to a formal dwelling and all households in the richest 25 per cent of households had access to a formal dwelling. A similar pattern of household access to formal dwelling can be seen in 1999 and 2004 . In fact, the same pattern is visible across all the variables contributing to relative asset wealth.

Variables that reflect relative asset poverty display a different trend. For example, in 1993, 65 per cent of households in the bottom 25 per cent of the distribution used candles as source of light. Use of candles decreased to 46 per cent of households in the next quartile, while only 4 per cent of households in the third quartile used candles as main source of light. None of the households in the top 25 per cent used candles as source of light.

Looking at the household asset variables (telecommunications, vehicle and television), for all three years household ownership of these assets increased when moving up the quartiles. This result is important for another reason. It shows a clear separation between poor and rich households on the durable asset variables too. This indicates that the asset index, while driven by household service variables also separates households clearly on the basis of their ownership of household durables.

\section{Robustness}

The robustness of the asset index is evaluated by comparing the results when different subsets of variables are used to construct the asset index. Two additional asset indices were constructed. The first asset index only included household characteristics variables, while the second index only included the three asset variables. The weights for these two indices can be found in Table D 2 . 
Table D 2: Scoring Coefficients for Asset Indices Constructed from Different Variables

\begin{tabular}{|c|c|c|c|}
\hline \multicolumn{4}{|c|}{ Asset Index based on Household Characteristics } \\
\hline Asset & Weight & Asset & Weight \\
\hline formal & 0.06962 & elect_lig & 0.14277 \\
\hline traditional & -0.05587 & para_lig & -0.03174 \\
\hline thatch_roof & -0.03672 & candle_lig & -0.07142 \\
\hline tile_roof & 0.04288 & elect_cook & 0.18295 \\
\hline Corr_roof & -0.03004 & para_cook & -0.02891 \\
\hline lowq_wall & -0.07685 & wood_cook & -0.07669 \\
\hline piped & 0.17676 & flush_chem & 0.19611 \\
\hline public & -0.04525 & pit & -0.05594 \\
\hline surface & -0.04255 & no_toilet & -0.04231 \\
\hline \multicolumn{4}{|c|}{ Asset Index based on Household Assets } \\
\hline Asset & Weight & & \\
\hline telecoms & 0.4332 & & \\
\hline vehicle & 0.32174 & & \\
\hline TV & 0.30389 & & \\
\hline
\end{tabular}

Source: PSLSD 1993 (SALDRU), OHS 1999 (Statistics SA), GHS 2004 (Statistics SA); Own Calculations

Following Filmer \& Pritchett (2001: 119) rank correlation coefficients were calculated to compare the degree to which the different methods produced the same ranking of households. Table D 3 below shows the rank order correlation between the three different indices for 1993 and 2004 (the results for 1999 are very similar and are not reproduced here). 
Table D 3: Rank Order Correlation between Asset Indices

\begin{tabular}{|l|r|}
\hline \multicolumn{1}{|c|}{1993} & \multicolumn{2}{c|}{ Full Index } \\
\hline \multicolumn{1}{|c|}{ Full Index } & 1 \\
\hline & 0.9809 \\
\hline Index with Household Characteristics & 0.7675 \\
\hline Index with Household Assets 2004 & 1 \\
\hline Full Index & 0.9727 \\
\hline Index with Household Characteristics & 0.7166 \\
\hline Index with Household Assets & \\
\hline
\end{tabular}

Source: PSLSD 1993 (SALDRU), OHS 1999 (Statistics SA), GHS 2004 (Statistics SA); Own Calculations

Notes: The Spearmen's correlation coefficients are significant at the 1 per cent level.

In 1993 the correlation of the index constructed with only household characteristic variables with the full index is 0.98 . The correlation of the full index with the index constructed with the three household characteristic variables is slightly lower but still significant at 0.77 . In 2004 the correlations are very similar at 0.97 and 0.72 respectively.

These results mean that, depending on the year, almost 100 per cent of household are ranked similarly when comparing the full asset index and the asset index constructed when factor analysis is performed on household characteristic variables only. While this may mean that the full asset index reflects household access to services to a larger degree, the fact is that more than 70 per cent of households are ranked similarly when comparing the full asset index the asset index constructed from household asset variables. In addition, the test for internal coherence has confirmed that there are very clear differences in household ownership of assets (durables) between relatively rich and poor households.

\section{Comparisons with other measures}

The final test involves comparing the asset index with other (more conventional) measures of poverty (Booysen, 2002: 64; Filmer \& Pritchett, 2001: 119). In our case we estimated the rank correlation of our asset index with monthly per capita household expenditure. Table D 4 presents the Spearman's Correlation Coefficients. 
Table D 4: Rank Correlation between the Asset Index and Per Capita Household Expenditure

\begin{tabular}{|l|c|}
\hline Year & Spearman's Correlation Coefficient \\
\hline 1993 & 0.7277 \\
\hline 1999 & 0.5149 \\
\hline 2004 & 0.5879 \\
\hline
\end{tabular}

Source: SLSD 1993 (SALDRU), OHS 1999 (Statistics SA), GHS 2004 (Statistics SA); Own Calculations

Notes: The Spearmen's correlation coefficients are significant at the 1 per cent level.

Our results indicate that in 1993 almost 73 per cent of households were ranked similarly when comparing the asset index to monthly per capita household expenditure. The correlation decreases to just over 50 per cent in $1999^{17}$ and picks up again to almost 60 per cent in 2004.

The decreasing correlation between expenditure and asset wealth can partly be explained by the fact that increased wealth have been driven by increased access to services/ household characteristics, which is delivery by government.

In addition, Table D 5 presents the mean values of the asset index according to per capita household expenditure deciles for all three years.

$17 \quad$ Note that the weaker correlation in 1999 may be partly due to the fact that around 10 per cent of the households surveyed in the 1999 October Household Survey did not report their household expenditure. 
Table D 5: Mean Values of the Asset Index according to Per Capita Household Expenditure Deciles, 1993, 1999 and 2004

\begin{tabular}{|l|r|r|r|}
\hline & \multicolumn{3}{|c|}{ Mean Value of Asset Index } \\
\hline Per Capita Household Expenditure Decile & \multicolumn{1}{|c|}{$\mathbf{1 9 9 3}$} & \multicolumn{1}{|c|}{$\mathbf{1 9 9 9}$} & \multicolumn{2}{c|}{$\mathbf{2 0 0 4}$} \\
\hline 1 & -1.25 & -0.63 & -0.61 \\
\hline 2 & -1.05 & -0.64 & -0.57 \\
\hline 3 & -0.86 & -0.56 & -0.35 \\
\hline 4 & -0.67 & -0.49 & -0.21 \\
\hline 5 & -0.46 & -0.37 & 0.00 \\
\hline 6 & -0.10 & -0.27 & 0.12 \\
\hline 7 & 0.19 & -0.09 & 0.37 \\
\hline 8 & 0.54 & 0.10 & 0.54 \\
\hline 9 & 0.83 & 0.42 & 0.79 \\
\hline 10 & 1.00 & 0.83 & 0.96 \\
\hline Total & $-\mathbf{0 . 1 8}$ & $-\mathbf{0 . 0 2}$ & $\mathbf{0 . 1 0}$ \\
\hline
\end{tabular}

Source: PSLSD 1993 (SALDRU), OHS 1999 (Statistics SA), GHS 2004 (Statistics SA); Own Calculations

Note: $\quad$ 1. The mean value of the asset index in this case refers to the mean value of the asset index for all households which recorded pc household expenditure, and differs very slightly from the mean values when all households are taken into account (as in Table 2).

2. Again, the figures for 1999 should be treated with caution as around 10 per cent of the households in dataset did not record their household expenditure.

With the exception of the bottom two expenditure deciles in 1999, the mean values of asset index increases as we move to higher per capita household expenditure deciles. This means that on average people who are less asset poor are also less expenditure poor. 


\section{Appendix E}

Poverty Shares by Race, 1993, 1999 and 2004

\begin{tabular}{|c|c|c|}
\hline & Poverty line 40th percentile & Poverty line 20th percentile \\
\hline & Headcount & Headcount \\
\hline \multicolumn{3}{|l|}{1993} \\
\hline African & $99.3 \%$ & $99.9 \%$ \\
\hline Coloured & $0.7 \%$ & $0.1 \%$ \\
\hline Asian & $0.0 \%$ & $0.0 \%$ \\
\hline White & $0.0 \%$ & $0.0 \%$ \\
\hline \multicolumn{3}{|l|}{1999} \\
\hline African & $97.5 \%$ & $98.8 \%$ \\
\hline Coloured & $2.2 \%$ & $1.2 \%$ \\
\hline Asian & $0.1 \%$ & $0.0 \%$ \\
\hline White & $0.3 \%$ & $0.0 \%$ \\
\hline \multicolumn{3}{|l|}{2004} \\
\hline African & $98.0 \%$ & $99.2 \%$ \\
\hline Coloured & $1.9 \%$ & $0.8 \%$ \\
\hline Asian & $0.0 \%$ & $0.0 \%$ \\
\hline White & $0.1 \%$ & $0.0 \%$ \\
\hline
\end{tabular}

Source: PSLSD 1993 (SALDRU), OHS 1999 (Statistics SA), GHS 2004 (Statistics SA); Own Calculations 


\section{Appendix F}

Poverty Shares by Location, 1993, 1999 and 2004

\begin{tabular}{|c|c|c|}
\hline & Poverty line 40th percentile & Poverty line 20th percentile \\
\hline & Headcount & Headcount \\
\hline \multicolumn{3}{|l|}{1993} \\
\hline Rural & $85.1 \%$ & $88.3 \%$ \\
\hline Urban & $14.9 \%$ & $11.7 \%$ \\
\hline \multicolumn{3}{|l|}{1999} \\
\hline Rural & $78.7 \%$ & $84.4 \%$ \\
\hline Urban & $21.3 \%$ & $15.6 \%$ \\
\hline \multicolumn{3}{|l|}{2004} \\
\hline Rural & $81.6 \%$ & $84.0 \%$ \\
\hline Urban & $18.4 \%$ & $16.0 \%$ \\
\hline
\end{tabular}

Source: PSLSD 1993 (SALDRU), OHS 1999 (Statistics SA), GHS 2004 (Statistics SA); Own Calculations 


\section{Appendix G}

Cumulative Distribution Functions for Urban Households, 1993, 1999 and 2004

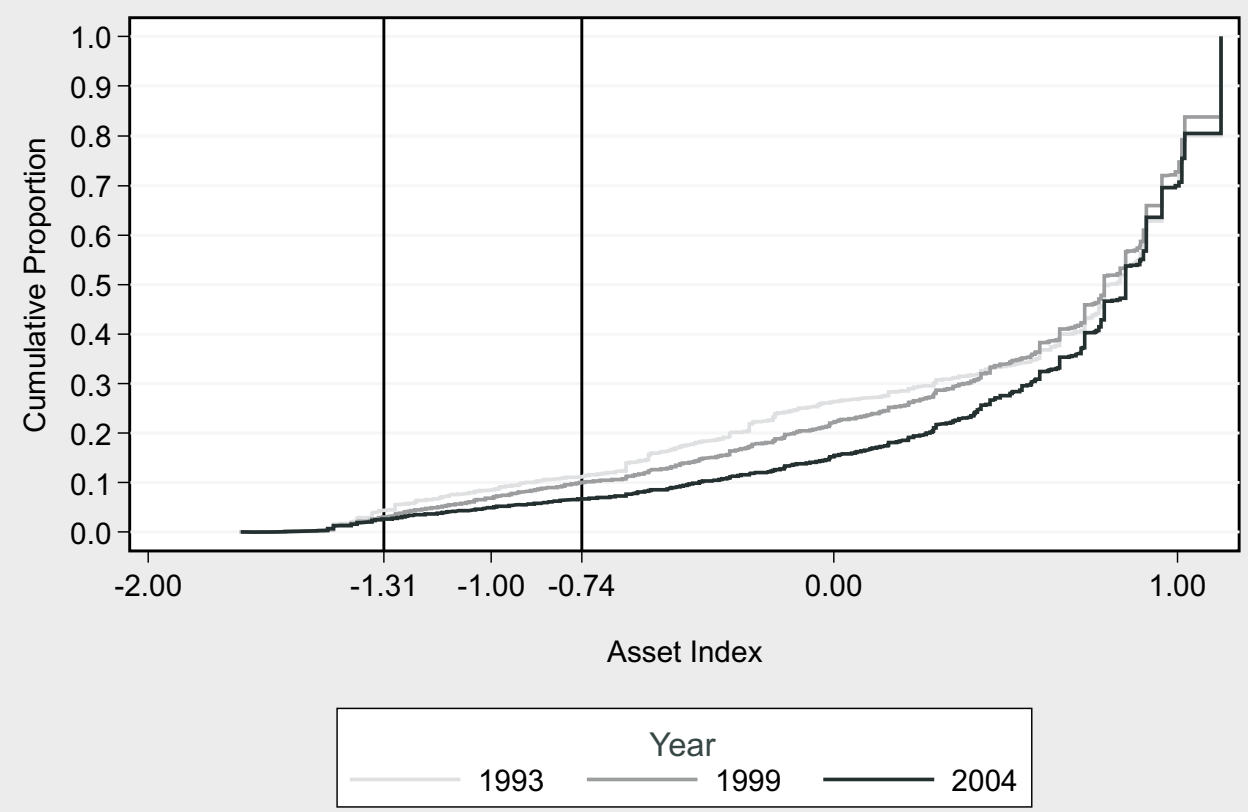

Source: PSLSD 1993 (SALDRU), OHS 1999 (Statistics SA), GHS 2004 (Statistics SA); Own Calculations 


\section{Appendix H: Cumulative Distribution Functions by Provinces}

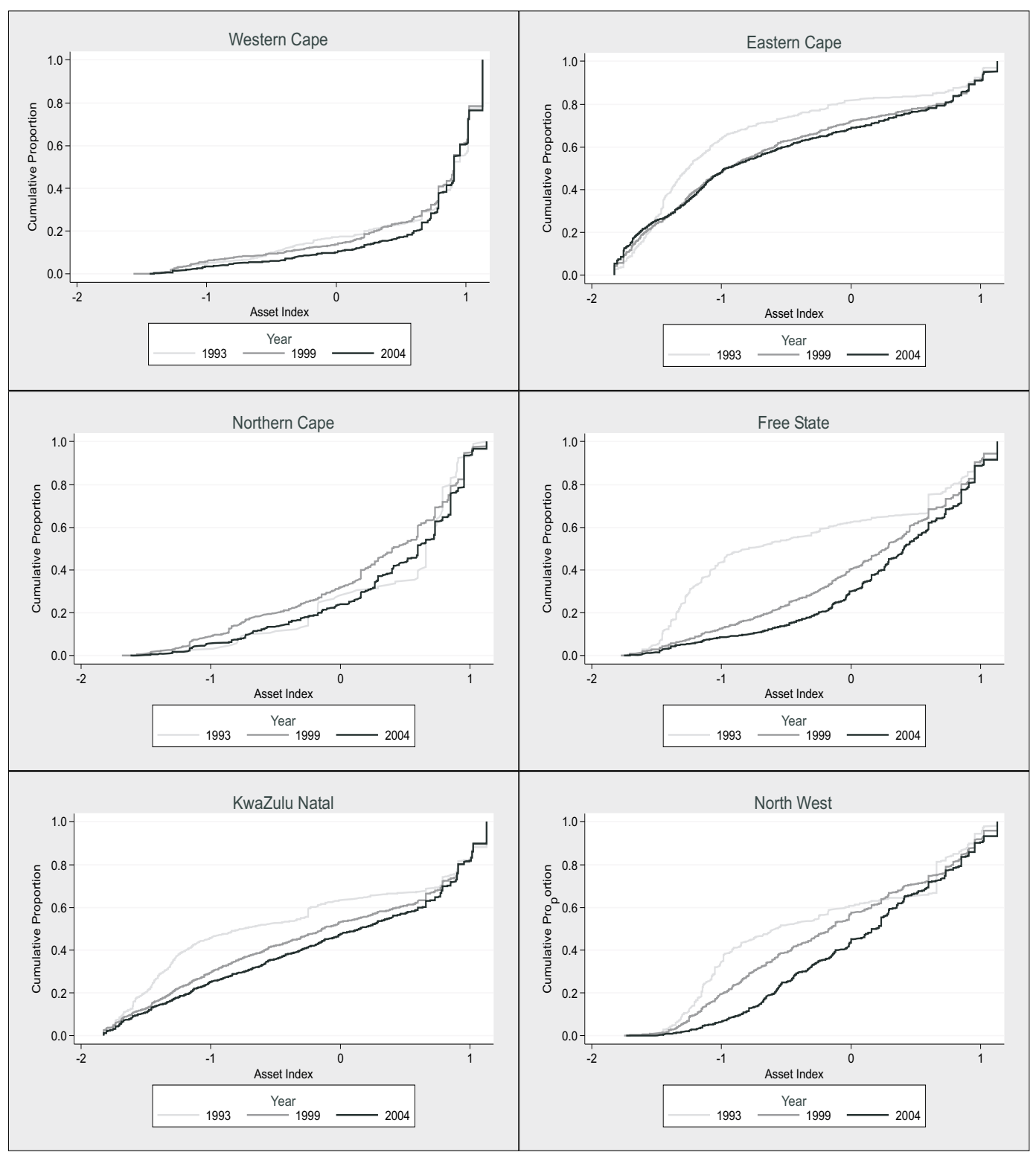




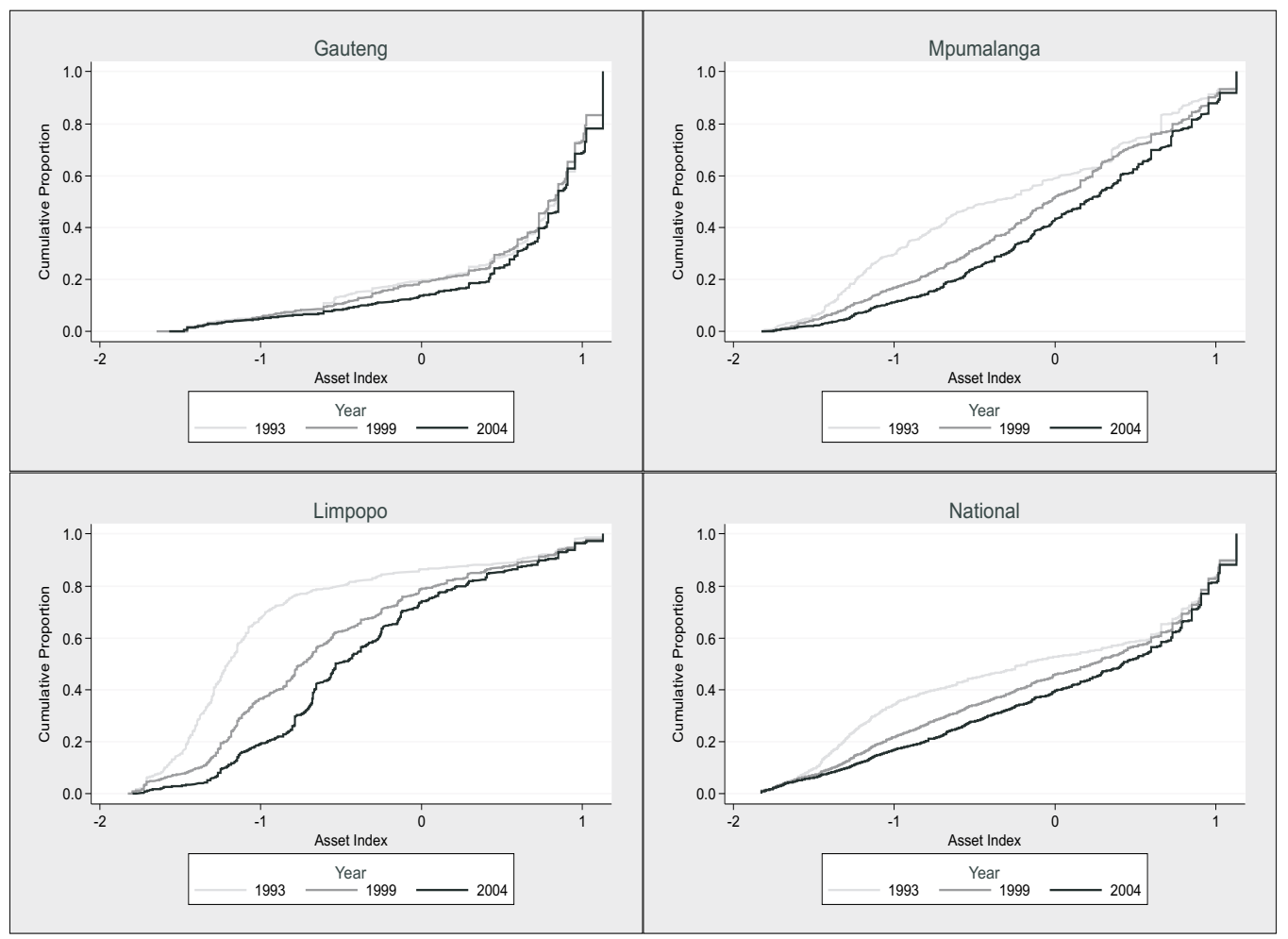

Source: PSLSD 1993 (SALDRU), OHS 1999 (Statistics SA), GHS 2004 (Statistics SA); Own Calculations 


\section{Appendix I}

Cumulative Distribution Functions for Rural African Households, 1993, 1999, 2004

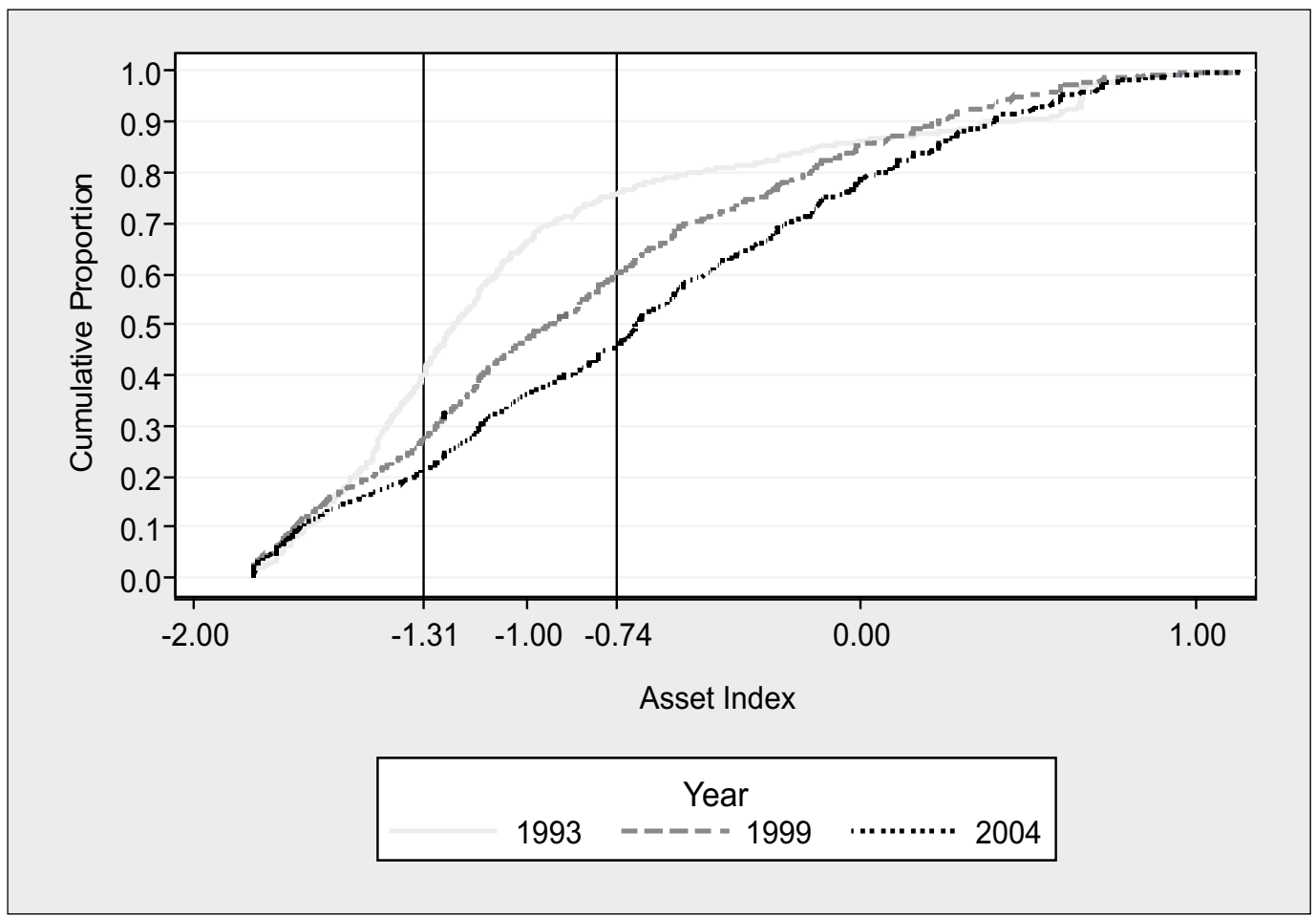

Source: PSLSD 1993 (SALDRU), OHS 1999 (Statistics SA), GHS 2004 (Statistics SA); Own Calculations 


\section{Appendix $\mathbf{J}$}

Poverty Shares by Gender of Household Head, 1993, 1999 and 2004

\begin{tabular}{|c|c|c|}
\hline & Poverty line 40th percentile & Poverty line 20th percentile \\
\hline & Headcount & Headcount \\
\hline \multicolumn{3}{|l|}{1993} \\
\hline Female & $35.4 \%$ & $36.7 \%$ \\
\hline Male & $64.6 \%$ & $63.3 \%$ \\
\hline \multicolumn{3}{|l|}{1999} \\
\hline Female & $47.8 \%$ & $50.7 \%$ \\
\hline Male & $52.2 \%$ & $49.3 \%$ \\
\hline \multicolumn{3}{|l|}{2004} \\
\hline Female & $49.6 \%$ & $52.4 \%$ \\
\hline Male & $50.4 \%$ & $47.6 \%$ \\
\hline
\end{tabular}

Source: PSLSD 1993 (SALDRU), OHS 1999 (Statistics SA), GHS 2004 (Statistics SA); Own Calculations 


\section{Appendix K}

Breakdown of Households According to Gender of Head, 1993, 1999 and 2004

\begin{tabular}{|c|c|}
\hline & Share of Total Households \\
\hline \multicolumn{2}{|l|}{1993} \\
\hline Female Headed & $28.3 \%$ \\
\hline Male Headed & $71.7 \%$ \\
\hline \multicolumn{2}{|l|}{1999} \\
\hline Female Headed & $37.6 \%$ \\
\hline Male Headed & $62.4 \%$ \\
\hline \multicolumn{2}{|l|}{2004} \\
\hline Female Headed & $37.1 \%$ \\
\hline Male Headed & $62.9 \%$ \\
\hline
\end{tabular}

Source: PSLSD 1993 (SALDRU), OHS 1999 (Statistics SA), GHS 2004 (Statistics SA); Own Calculations 


\section{Appendix L}

Decomposition of Inequality by Race, using the Theil-index

\begin{tabular}{|l|r|r|r|}
\hline & 1993 & $\mathbf{1 9 9 9}$ & $\mathbf{2 0 0 4}$ \\
\hline Within-group inequality & 0.11475 & 0.10143 & 0.09037 \\
\hline Between-group inequality & 0.06621 & 0.03025 & 0.01995 \\
\hline Total Inequality & 0.18096 & 0.13168 & 0.11032 \\
\hline
\end{tabular}

Source: PSLSD 1993 (SALDRU), OHS 1999 (Statistics SA), GHS 2004 (Statistics SA); Own Calculations

Decomposition of Inequality by Location, using the Theil-index

\begin{tabular}{|l|r|r|r|}
\hline & 1993 & 1999 & $\mathbf{2 0 0 4}$ \\
\hline Within-group inequality & 0.10923 & 0.08393 & 0.07248 \\
\hline Between-group inequality & 0.07172 & 0.04788 & 0.03784 \\
\hline Total Inequality & 0.18096 & 0.13181 & 0.11032 \\
\hline
\end{tabular}

Source: PSLSD 1993 (SALDRU), OHS 1999 (Statistics SA), GHS 2004 (Statistics SA); Own Calculations

Decomposition of Inequality by Gender of Household Head, using the Theil-index

\begin{tabular}{|l|r|r|r|}
\hline & 1993 & 1999 & $\mathbf{2 0 0 4}$ \\
\hline Within-group inequality & 0.17711 & 0.12802 & 0.10713 \\
\hline Between-group inequality & 0.00374 & 0.00384 & 0.00323 \\
\hline Total Inequality & 0.18084 & 0.13186 & 0.11036 \\
\hline
\end{tabular}

Source: PSLSD 1993 (SALDRU), OHS 1999 (Statistics SA), GHS 2004 (Statistics SA); Own Calculations 